\title{
Development and Evaluation of Lyophilized Methotrexate Nanosuspension using Quality by Design Approach
}

\author{
Trupti Powar, ${ }^{1,}$ Ashok Hajare, ${ }^{2}$ Ravindra Jarag ${ }^{3}$ and Sopan Nangare ${ }^{4}$ \\ ${ }^{1}$ Department of Pharmaceutics, Smt. Kashibai Navale College of Pharmacy, Kondhwa, Pune (Maharashtra) 411048, India. \\ ${ }^{2}$ Department of Pharmaceutics, Bharati Vidyapeeth College of Pharmacy, Kolhapur (Maharashtra) 416013, India. \\ ${ }^{3}$ Department of Pharmacology, Bharati Vidyapeeth College of Pharmacy, Kolhapur (Maharashtra) 416013, India. \\ ${ }^{4}$ Department of Pharmaceutics, H. R. Patel Institute of Pharmaceutical Education and Research, \\ Shirpur (Maharashtra) 425405, India. \\ *Corresponding author: E-mail: E-mail: truptipowar51@gmail.com \\ Mobile: +919766196512
}

Received: 06-29-2021

\begin{abstract}
With the application of the quality by design $(\mathrm{QbD})$ approach, a high-pressure homogenizer ( $\mathrm{HPH})$ methodology was employed to develop methotrexate nanosuspension (MTX-NS) to boost bioavailability. The Ishikawa diagram was used to analyze potential risk factors in formulation development. To screen and study the impact of various formulation and process factors on the critical quality attributes (CQA), the Placket-Burman design and central composite design were utilized. The number of HPH cycles, poloxamer 188 concentration, and tween 80 concentration were shown to be significant parameters $(\mathrm{P}<0.05)$, that were further optimized using Central Composite Design. The zeta potential of optimized lyophilized MTX-NS was determined to be $-11.6 \pm 7.52 \mathrm{mV}$ and the average particle size was $260 \pm 0.25 \mathrm{~nm}$. In vitro cytotoxicity experiments revealed a greater than $80 \%$ inhibition, with apoptotic cells shrinking, fragmentation, and cell death. Furthermore, the $\mathrm{C}_{\max }$ and $\mathrm{AUC}_{0-\mathrm{t}}$ were increased by 2.53 and 8.83 folds, respectively. The relative bioavailability of MTX-NS was found to be 8.83 times higher than that of MTX-aqueous dispersion. As a result, the QbD method resulted in the development of a lyophilized MTX-NS with process understanding and control based on quality risk management.
\end{abstract}

Keywords: Nanosuspension; Lyophilized, QbD approach; Central Composite Design; Plackett- Burman Design; In-vivo study.

\section{Introduction}

Pharmaceutical experts have long struggled with the formulation and development of poorly water-soluble drugs, and these challenges are projected to worsen since more than $40 \%$ of new chemical entities discovered by drug discovery are poorly aqueous soluble. ${ }^{1}$ Whereas, it is more problematic in the case of poorly soluble drugs with poor absorption profile, and bioavailability because it is dissolution rate-limited and can be affected by patient fed or fasted state condition ${ }^{2}$. Traditional approaches including solubilization by surfactant, surfactant dispersion, micronization, use of the oily solution, permeation enhancers, which evolved too earlier, that address the challenges of formulation and have limited use. ${ }^{2,3}$ The major mile- stone has been achieved in the development of poorly water-soluble drugs using various newer technology, but to date, there is no universal thumb approach applicable to all active pharmaceutical ingredients. ${ }^{3}$ Consequently, a new approach has been progressively required to deal with formulation issues that are associated with the delivery of poorly soluble drugs, to enhance their therapeutic efficacy and maximize their pharmacodynamics therapy. ${ }^{2}$

A drug delivery aims to deliver a sufficient amount of drug to a proper side in the body such that, the optimal concentration of the drug is reached rapidly and then sustained. The development of a proper dosage form is an essential element to achieve this objective. ${ }^{4}$ From its inception, oral drug delivery is the most commonly used route of administering the drug in various dosage forms due to 
its simple administration, flexibility in the design of dosage form, and its high patient compliance. ${ }^{5}$

The Methotrexate (MTX) (2, 4-diamino-N10-methyl propyl glutamic acid) is an anticancer agent belong to biopharmaceutical classification system class IV (BCS-IV) employed for different solid tumors viz. Breast cancer, lung cancer, etc. treatment. ${ }^{6}$ It has poor water solubility $(0.01 \mathrm{mg} / \mathrm{mL})$, low permeability hence consequently very low bioavailability $(30-40 \%))^{7,8}$ Besides, MTX showed multidrug resistance (MDR) in cancer treatment and produced toxicity to a normal cell of the body. Also, MTX produces several adverse reactions like hepatotoxicity, ulcerative colitis, nephrotoxicity, which resulted in the restriction of its clinical applications. ${ }^{7}$

Nano-formulation is a comparatively new scientific field that applies Nano-engineering to health and medicines. Although nanotechnology has multiple applications in the drug delivery system, the development of nanoparticles (nanoscale: $10^{-9} \mathrm{~m}$ ) based formulation has been a key application in pharmaceuticals. ${ }^{3}$ In recent decades, nanoparticle engineering for pharmaceutical applications has been developed and reported by researchers. ${ }^{9}$ Among the assorted strategy of conversion of nanoparticles, $\mathrm{Na}$ nosuspension (NS) is offering plentiful advantages over conventional oral drug delivery. NS can be defined as a sub-micron colloidal dispersion of nanosized (1-1000 $\mathrm{nm})$ pure drug particles that are stabilized by surfactant/ polymer or a mixture of both. ${ }^{10} \mathrm{NS}$ is gaining a lot of attention in the scientific community because of its numerous benefits, including improved dissolution rate and, as a result, increased bioavailability of poorly soluble and permeable drugs, improved physical and chemical stability of drugs, higher drug loading, dose reduction, and so on ${ }^{2,3} \mathrm{It}$ also improves the AUC and $\mathrm{C}_{\max }$ of the drug and consequently improves drug safety and efficacy. ${ }^{11}$ Besides, in the last two decades, NS has been drawing much attention in the pharmaceutical industry and also has been executed commercially..$^{10}$ For productive formulation development of the NS various strategy have been reported including top-down (viz. high-pressure homogenization, sonication, etc.) and bottom-up approach (viz: nano-precipitation), etc. ${ }^{3,11,12}$

For the production of nanosuspensions of poorly soluble medicines, high pressure homogenization is a typical approach. This procedure entails forcing a drugand-stabilizer suspension through a valve with a small opening under pressure. High-pressure homogenization is usually divided into two categories: (i) Dissocubes (aqueous media homogenization), (ii) Nanopure (homogenization in water-free media or water mixtures). The size of the particles is reduced in homogenization by forcing suspension under high pressure (100-1000 bars) through a small-aperture valve. Cavitation-induced implosion pressures and shock waves in the liquid medium break down microparticles $(25 \mathrm{~m}$ ) into the nano-size range as the static pressure drops due to a sudden drop in fluid velocity. Shear forces caused by particle collisions and high velocity also aid in the fracture of particles with inherent crystal flaws. Viscosity enhancers can aid the nanosizing process by increasing particle density inside the dispersion area and inhibiting crystal formation. Homogenization can convert metastable amorphous particles generated by precipitation into stable crystal form. To create particles in the desired size ranges, numerous cycles are usually required. The method's main advantages are its ease of scaling up, adaptability to dilute or concentrate suspensions, low risk of contamination, and aseptic manufacturing viability. The approaches include difficulties such as the need for micronized particles, multiple cycles, high energy technique, and the danger of contamination from the container's metal wall. ${ }^{13-16}$

Further, the physical stability problem of NS has been overcome by various solidification techniques including rotary evaporation, spray drying, lyophilization, etc. Generally, the technique selection has been done based on the physical properties of active pharmaceutical ingredients and the characteristics of the final formulation. ${ }^{10}$ Among these techniques, lyophilization is predominately employed for the solidification of NS, which provides several benefits such as suitability for drying of thermolabile drugs, enhanced long-term storage stability, easy reconstitution of the formulation before use, and manufacture of high-value formulation without excessive damage. ${ }^{10,11}$ Furthermore, the development of an oral drug delivery system for anticancer drugs provides the most suitable and easiest way. ${ }^{7}$ Therefore, the development of MTX in lyophilized NS form can be a useful tool to attempt the above-mentioned facts.

Owing to the fast onset of action, permeability, solubility, and bioavailability, a novel drug delivery system (NDDS) is well known for its toxicities. Whereas, the cost of such an advanced NDDS is increasing because of a lack of proper understanding and various manufacturing variability. ${ }^{11}$ The International Conference on Harmonization (ICH Q8) proposed to use the concepts of quality by design $(\mathrm{QbD})$ to formulate the pharmaceutical products as technical criteria. ${ }^{17}$ Owing to the high incomprehension about the effect of critical processing parameters (CPPs), critical material attributes (CMAs) on the attainment of admirable smaller particle size, and narrow polydispersity index (PDI), researchers stressed for the most challenging manufacturing variability during NS formulation development. ${ }^{11}$

Hence, the present study is aimed to develop MTXNS to improve its oral bioavailability that can increase its clinical efficacy by reducing the oral dose which is required to achieve the same effect and thus reduces its side effects. $\mathrm{QbD}$ approach was applied to obtain the effect of CMAs and CPPs on critical quality attributes (CQAs) viz., particle size, drug content, zeta potential, dissolution profile and bioavailability of MTX-NS, reduction in the manufacturing variability, upgrading of safety and quality in a for- 
mulation, and controlling the manufacturing cost. QbD approach was applied to understand and optimize the lyophilized preparation of MTX-NS. In the first step, all the possible potential independent variables were screened by the Plackett-Burman design. A predictive model was then developed for critical response variables to evaluate optimal value by Central composite design (CCD) to produces extremely stable and soluble MTX-NS by the High-Pressure Homogenizer (HPH) technique. The MTX-NS developed was stabilized using the lyophilization process. The MTX-NS was evaluated for their saturation solubility, particle size, and zeta potential analysis, polydispersity index (PDI), crystallinity study, topographical analysis, dissolution efficiency, Apoptosis, and in-vitro cytotoxicity study. Moreover, the in vivo bioavailability and stability study of MTX-NS was also performed.

\section{Material and Methods}

\section{1. Materials}

MTX sample was gifted by Cipla Ltd, Goa (India). Tween 80 and mannitol (MNT) was procured from Merck Specialties Pvt. Ltd. Mumbai, (India). Soya lecithin (SL) (Phospholipon R $90 \mathrm{H}$ ) was obtained from Lipoid $\mathrm{GmbH}$ (Germany). HPLC grade methanol was purchased from Thermo Fisher Scientific Pvt. Ltd. Mumbai, (India). All other reagents used in the experiments were of analytical grade.

\section{2. Methods}

\section{2. 1. Screening of the Stabilizer and Polymers for MTX-NS}

For the formulation development of MTX-NS, appropriate stabilizers were obtained from 20 stabilizers as enlisted beneath.

\section{2. 1. 1. Suspending Effect of Stabilizers}

Initially, the suitable polymers and stabilizers were screened based on suspending concentration of stabilizers viz., Carbomer 940, cremophor EL-40, poloxamer 407, soya lecithin (SL), hydroxypropyl methylcellulose (HPMC), tween 80, sodium lauryl sulfate (SLS), poloxamer 188 (F68), polyethylene glycol (PEG) 6000, span 80, sodium deoxycholate (SDS), polyvinyl pyrrolidone (PVP) K 30 , and/or their mixtures on MTX. About $0.5 \mathrm{mg}$ of MTX was added in $0.2 \% \mathrm{w} / \mathrm{v}$ surfactant solution, followed by shearing with a high-speed homogenizer for $1.5 \mathrm{~h}(3000$ $\mathrm{rpm}$ ), followed by centrifugation at $4000 \mathrm{rpm}$ for $30 \mathrm{~min}$ duration. The supernatant was diluted using water as a solvent and drug content was measured by UV visible spectrophotometer at $303 \mathrm{~nm}$. As composites for the development of NS, the stabilizer which has shown an effective suspending effect on MTX, smaller particle size, and lower sedimentation rate were optimized. ${ }^{18-20}$

\section{2. 1. 2. Docking Tool and Algorithm}

The virtual interaction among MTX and above-enlisted stabilizers were performed via molecular docking using VLife MDS version 4.6. The chemical structures of enlisted stabilizers and MTX were drawn in a 2D format which was followed by $3 \mathrm{D}$ conversion. Finally, these structures were optimized for the docking score. Generally, biopredicta (docking algorithm) is used to predict and study the modes of interaction between two compounds. Herein, the possible interaction between stabilizers and MTX was optimized based on ligand-receptor binding geometry within chemical structures of compounds. Finally, the molecular interaction among stabilizers and MTX were screened to establish the stabilizer's ability to enhance drug solubility and NS stability purpose.

\section{2. 2. Formulation and Lyophilization of MTX-NS}

MTX-NS was fabricated by HPH (Panda PLUS 2000, GEA Niro Soavi, Germany). Pre-nanosuspension was first fabricated using a high-speed homogenizer to avoid blockage of the HPH valve. Here, the $0.5 \mathrm{mg} / \mathrm{mL}$ coarse powder of MTX was ${ }^{17}$ dispersed in an aqueous stabilizer solution of $(0.15 \% \mathrm{v} / \mathrm{v}$ tween 80 and $30 \mathrm{mg}$ of SL) by digital homogenizer $(3000 \mathrm{rpm}, 1.5 \mathrm{~h})$. Then, the pre-NS was subjected to $\mathrm{HPH}$ processing, with three HPH cycles at fixed 250, 700 , and 1200 bars. Moreover, this obtained NS was shifted for 1500 bars for maximum cycles. Interestingly, the number of cycles of HPH at constant process temperature can affect the particle size of the formulation. Therefore the MTX-NS showed different particle sizes, concerning process temperature and several cycles. Finally, the obtained NS was shifted to the lyophilization process using a lyophilizer (Freezone12, Labconco, MO, USA) along with the optimized concentration of cryoprotectant $(6 \% \mathrm{w} / \mathrm{w}$ mannitol). Initially, the pre-freezing of MTX-NS was performed at $-30^{\circ} \mathrm{C}$ for $12 \mathrm{~h}$. Then, the primary drying process of NS was performed at $-53^{\circ} \mathrm{C}$ and $0.016 \mathrm{mBar}$ for 24 h. Finally, the secondary drying was carried out at $10^{\circ} \mathrm{C}$ for $8 \mathrm{~h}$ followed by $25^{\circ} \mathrm{C}$ for $4 \mathrm{~h}$. Further drying of obtained lyophilized NS was done by gradually increasing the drying process temperature by $1{ }^{\circ} \mathrm{C} / \mathrm{min}$. to finish the process. The temperature of the cold trap was maintained at $-53{ }^{\circ} \mathrm{C}$ until the end of the drying process.

\section{2. 3. Quality by Design}

\section{2. 3. 1. Quality Target Product Profile (QTPP)}

The primary step in $\mathrm{QbD}$ is to define the potential target product profile (TPP) and critical quality attributes (CQA) of the formulation. To this study, the CQAs were enlisted based on a literature survey and preliminary research on the formulation. For the study, CMAs, CPPs have been chosen to satisfy the predefined objective. ${ }^{22}$ The QTPP, CMAs, and CPPs listed are presented in Table S1. 


\section{2. 3. 2. Risk Assessment}

In the context of risk assessment, the main critical material and process parameters that influence the formulation quality were established. An Ishikawa fishbone diagram is also referred to as a cause-effect diagram, developed to define the CPPs and CMAs. Only three-parameter were indicated as important factors influencing formulation i.e. drug content (DC), and average particle size, as CQAs following the risk analysis using the diagram and preliminary studies In addition, failure mode effects analysis (FMEA) was utilized for risk assessment, followed by risk rating and filtering following the ICH Q9 recommendations. As shown in Table S2, the risk associated with each element [critical method parameters (CMPs) and critical process parameters (CPPs)] on responses was critically assessed, and the risks were then labeled using the FMEA approach, which measures risk severity. Severity (effect on end method output), regularity of occurrence, and detectability are three major categories which were all used further to define risk variables. The impact of these factors on responses was evaluated from 1 to 3 scale (Table S3). Table S3 lays up the rankings. The sum of the severity, regularity, and detectability was used to calculate the risk priority number (RPN). As stated in Table S4, the RPN values were utilized to rank failure modes, CMPs, and CPPs. ${ }^{21,23,22,30}$

\section{2.3. 3. Experimental Design}

Eight independent variables were selected based on risk analysis, (Table 1) namely speed of high-speed homogenizer (pre-NS) (X1), time of homogenizer (pre-NS) (X2), homogenization pressure (X3), number of cycles (X4), the concentration of poloxamer 188 (X5), the concentration of sodium lauryl sulfate (X6), the concentration of tween 80 (X7), the concentration of MTX (X8). For the optimization study of NS, the response surface method was employed. Furthermore, each of these factors were evaluated at two levels, including six center points; Plackett-Burman Design (PB design) was used to study the effect of these variables on the preparation of NS. Design-Expert (Version11.0.5.0, Stat-Ease Inc., MN) software was used for the analysis of three response variables viz., particle size (Y1), and DC (Y2). The experiment was conducted in random order according to the runs or trials organized by design expert software. Besides, the variable analysis (ANOVA) was used to estimate the significance of interaction and key effects. Factors that have a marginal effect on the reaction variables at a significance level of $95 \%$ have been analyzed and CCD further optimizes the remaining important factors influencing the response variables.

\section{2. 3. 4. Central Composite Design (CCD) for Optimization of MTX-NS}

After the identification of critical formulation and process variables using $\mathrm{PB}$ screening design, CCD response surface methods were used to inspect the optimum levels of the variables. This consisted of two groups of design points, which include two-level factorial design points as -1 and +1 , axial, or star points as $-\alpha$ and $+\alpha$ along with center points as 0 . Thus, the effect of three independent variables viz., the concentration of tween $80(\mathrm{~A})$, the concentration of poloxamer $188(\mathrm{~B})$, and the number of cycles (C) was studied at five different levels, with the coding of $-\alpha,-1,0,+1$, and $+\alpha$. Alpha value, 1.6817 fulfills the rotatability in the CCD. Dependent variables selected for the formulation of MTXNPs by CCD were particle size (Y1), \& DC (Y2). Table 2 suggests the coded and actual values of variables. The Design Expert ${ }^{\oplus}$ software was used to gener-

Table 1. Plackett-Burman Design with independent variables and their responses

\begin{tabular}{llcc}
\hline Factors & \multicolumn{2}{c}{ Levels } \\
& & High & Low \\
\hline X1 & Speed of Homogenizer (Preliminary Stage) (rpm) & 8000 & 6000 \\
X2 & Time of Homogenizer (Preliminary Stage) (min.) & 45 & 30 \\
X3 & Homogenization Pressure (Bars * 1000) & 25 & 5 \\
X4 & Number of Cycles & 25 & 5 \\
X5 & Concentration of Poloxamer 188 (mg) & 75 & 50 \\
X6 & Concentration of Sodium Lauryl Sulphate $(\mathrm{mg})$ & 75 & 50 \\
X7 & Concentration of Tween 80 (mL) & 0.75 & 0.50 \\
X8 & Concentration of Methotrexate (mg) & 150 & 100 \\
\hline
\end{tabular}

Table 2. Central Composite Design with factors and their responses

\begin{tabular}{llccccc}
\hline & Factors & \multicolumn{3}{c}{ Levels } & \\
& & $-\boldsymbol{\alpha}$ & $\mathbf{- 1}$ & $\mathbf{0}$ & $\mathbf{+ 1}$ & $+\boldsymbol{\alpha}$ \\
\hline A & Concentration of Tween 80 (mL) & 0.05 & 0.15 & 0.25 & 0.35 & 0.45 \\
B & Concentration of Poloxamer 188 (mg) & 25 & 50 & 75 & 100 & 125 \\
C & Number of cycles & 10 & 20 & 30 & 40 & 50 \\
\hline
\end{tabular}


ate a CCD matrix with 20 runs, which includes six replicated center points, one axial point, and one replication of fractional point.

\section{2. 4. Process Analytical Technology (PAT) - Particle Size Analysis, EE, and DC}

The particle size analysis of developed NS was measured by Zetasizer 300 HAS (Malvern Instruments, Malvern, UK). The DC were calculated by using a UV-visible spectrophotometer (Jasco V-530, Japan) at $303 \mathrm{~nm}$ wavelengths. It was used for PAT for NS particle size, and DC. ${ }^{23,24}$

\section{2. 5. Characterization of MTX-NS}

\section{2. 5. 1. Particle Size Analysis}

MTX-NS particle size, polydispersity index (PDI), and zeta potential were measured at $25^{\circ} \mathrm{C}$ by dynamic light scattering (DLS) method using Zetasizer 300 HAS (Malvern Instruments, Malvern, UK) in triplicates in a 1 $\mathrm{ml}$ disposable polystyrene cuvette. For sample preparation, the $1 \mathrm{mg}$ of lyophilized MTX-NS was diluted in $10 \mathrm{ml}$ water, and analysis was performed for independent samples $(n=6.18)$. The values shown on average are the hydrodynamic sample diameter and the PDI value measured is the size distribution width. Besides, the zeta potential of NS was measured at the above-mentioned zeta sizer. It is determined at an average of measurements based on the electrical mobility of particles in an electric field. ${ }^{11,24}$

\section{2. 5. 2. Scanning Electron Microscopy (SEM)}

The morphology of MTX-NS was determined by SEM (JEOL JSM-6360, Japan). Imaging was performed on SEM at a voltage of $20 \mathrm{kV}$ and a high vacuum. Lyophilized MTX-NS was placed on two-sided carbon tape and sputtered using gold-palladium alloy (3-5 nm of thickness) and imaging was captured using SEM. ${ }^{25}$

\section{2. 5. 3. X-ray Crystallography (XRD)}

Powder XRD analysis of pure drug, physical mixture (PM), and optimized NS were performed using an X-ray diffractometer (Philips analytical XRD, PW 3710) with $\mathrm{Cu}-\mathrm{Ka}$ radiation $(1.54 \AA$ ), at $40 \mathrm{kV}, 40 \mathrm{~mA}$ by passing through a nickel filter. The samples were prepared by spreading the powder samples on the specimen holding ring and further it was subjected to sample angular scan. The samples were analyzed in the $2 \theta$ angle range of 5 to $80^{\circ}$. The range and the chart speed were $5 \times 10^{3} \mathrm{CPS}$ and $10 \mathrm{~mm} /{ }^{\circ} 2 \theta$, respectively. ${ }^{25}$

\section{2. 5. 4. Differential Scanning Calorimetry (DSC)}

The samples of pure drug, physical mixture (PM), and optimized NS were accurately weighed and filled in aluminum pans followed by a sealing process and then shifted to DSC using Perkin-Elmer Pyris 6 DSC, coupled with Pyris software and equipped with a thermal analyzer (Perkin-Elmer Instruments, Norwalk, USA). Thermo grams were taken from 35 to $300{ }^{\circ} \mathrm{C}$ with a heating rate of $10{ }^{\circ} \mathrm{C} \mathrm{min}^{-1}$ using a bare aluminum pan as a reference by heating the sample in the nitrogen atmosphere. ${ }^{11}$

\section{2. 5. 5. Fourier Transform Infrared Spectroscopy (FTIR)}

The FTIR of the drug, physical mixture (PM), and optimized lyophilized NS were obtained using the FTIR spectrophotometer (Agilent CARY 630 FTIR). The abovementioned samples were crushed to a fine powder, mulled with potassium bromide, and pressed to form a thin pellet, and subjected to analysis. ${ }^{25}$

\section{2. 5. 6. Saturation Solubility Studies}

Excess pure drug (MTX) and lyophilized MTX-NS in $10 \mathrm{~mL}$ of distilled water were added to their saturation, followed by agitation using an orbital shaker for $48 \mathrm{~h}$ at 25 ${ }^{\circ} \mathrm{C}$. The obtained samples were subjected to centrifugation. Then the supernatant layer was analyzed using a UV-visible spectrophotometer at $303 \mathrm{~nm} .{ }^{11,26}$

\section{2. 5. 7. Total Drug Content}

About $10 \mathrm{mg}$ of MTX-NS was dissolved in water followed by filtration using $0.45 \mu \mathrm{m}$ filter paper. Finally, the filtrate was collected and subjected to total DC analysis using a UV-visible spectrophotometer (Shimadzu-1700, Japan) at $\lambda$ max of $303 \mathrm{~nm}$. The total DC (TDC) and percentage TDC were calculated from equations 1 and $2 .^{20}$

$\mathrm{TDC}=($ Vol. total/ Vol. aliquot $) \mathrm{x}$ drug in aliquot $\mathrm{x} 100$

$\% \mathrm{TDC}=\mathrm{TDC} / \mathrm{TAD} \times 100$

where, TAD: vol. total/vol. an aliquot is the total volume of NS to the taken aliquot volume and the total amount of drug i.e. TAD is the drug used for the fabrication of NS.

\section{2. 5. 8. Entrapment Efficiency}

About $10 \mathrm{mg}$ of MTX-NS was dissolved in $10 \mathrm{ml}$ of water and \% EE was determined by ultracentrifugation for $30 \mathrm{~min}$ at $10,000 \mathrm{rpm}$ using a cold centrifuge (at $4{ }^{\circ} \mathrm{C}$, Remi CM 12 Plus, Mumbai). The supernatant obtained was quantified in triplicates at $303 \mathrm{~nm}$ using a UV-visible spectrophotometer. EE is the percentage of drug entrapped in nanoparticles and can be calculated using a given formula. ${ }^{11,29}$

$$
\% \mathrm{EE}=\frac{\text { Total drug content }(\mathrm{mg})-\text { Free Drug }(\mathrm{mg})}{\text { Total drug content }(\mathrm{mg})} X 100
$$

\section{2. 5. 9. In-vitro Drug Release}

Dissolution studies on MTX powder and optimized MTX-NS were performed using USP type-I apparatus (Basket). About $50 \mathrm{mg}$ of weighed quantities of samples 
were transferred into the dissolution apparatus (Electro lab TDT-08 L, India) containing $900 \mathrm{~mL}$ of simulated intestinal fluid (SIF) with $\mathrm{pH} 6.8$ as a medium at $50 \mathrm{rpm}$ with $37 \pm 0.5{ }^{\circ} \mathrm{C}$ temperature. For analysis, $5 \mathrm{~mL}$ samples were withdrawn at $10,20,30,40,50$, and $60 \mathrm{~min}$. of time points, and the fresh buffer was added for sink condition maintenance. The samples were collected and filtered using the Whatman filter paper $(0.25 \mu \mathrm{m}$, Whatman Inc., USA) and subjected to UV spectrophotometer analysis at $303 \mathrm{~nm}^{.}{ }^{19}$

\section{2. 5. 10. Cytotoxicity Activity on Human Breast Cancer Cell Line (MCF-7 Cells)}

Cell Culture: Cytotoxicity of optimized MTX-NS and aqueous dispersion (AQD) was studied on human MCF-7 breast cancer cell lines, which were procured from NCCS (National Centre for Cell Sciences), Pune, India. They were stored and nurtured in DMEM (Dulbecco's modified eagles medium of Sigma Aldrich, USA). Cell lines were cultured and maintained in a $25 \mathrm{~cm}^{2}$ flask of tissue culture with DMEM which was boosted with L-glutamine, $10 \%$ FBS, sodium bicarbonate (Merck, Germany), and with an antibiotic solution containing streptomycin $(100 \mu \mathrm{g} / \mathrm{ml})$, amphotericin B $(2.5 \mu \mathrm{g} / \mathrm{ml})$ and penicillin $(100 \mathrm{U} / \mathrm{ml})$. These cultured cells were then kept in a $\mathrm{CO}_{2}$ incubator at $37^{\circ} \mathrm{C}$ with $5 \%$ humidity.

MTT assay: In each well of 96 well microtiter plates, about $50 \mu \mathrm{L} 1 \times 10^{5}$ cells $/ \mathrm{mL}$ cell suspension was seeded and end volume was made to $150 \mu \mathrm{L}$ by adding DMEM media. Dilutions of NS were made in DMEM media and about $100 \mu \mathrm{L}$ of different concentrations of NS and their aqueous dispersion (AQD) $(62.5,125,250,500,1000 \mu \mathrm{g} /$ $\mathrm{mL}$ ) were added and incubated for $48 \mathrm{~h}$ in presence of $\mathrm{CO}_{2}$ incubator at $37{ }^{\circ} \mathrm{C}$ with $5 \%$ humidity. After $48 \mathrm{~h}, 20 \mu \mathrm{L}$ 3-(4,5-dimethylthiazol-2-yl)-2,5-diphenyl tetrazolium bromide (MTT) reagent $(5 \mathrm{mg} / \mathrm{mL})$ was added to the wells and the plates were kept for $4 \mathrm{~h}$ to incubate in a dark place at room temperature. The plates were covered with aluminum foil as the MTT reagent is photosensitive. Without disturbing the precipitated formazan crystals, the supernatant was removed carefully and $100 \mu \mathrm{L}$ dimethyl sulfoxide (DMSO) was added to dissolve the formed crystals. The OD (optical density) was measured using the ELISA microplate reader at $492 \mathrm{~nm}$. The baseline was obtained using a culture medium and the wells with only cells were used as control. With an assessment of colorimetry and spectrophotometry, the in-vitro growth inhibition effect of NS and AQD was measured by the conversion of MTT into "Formazan blue" by living cells. The study was performed in triplicates. The generated dose-response curve was used to estimate the $\mathrm{IC}_{50}$ of test samples required to inhibit the growth of $50 \%$ cells. The $\%$ growth inhibition was calculated using the following formula (equation 4),

\section{2. 5. 11. Direct Microscopy}

The entire plate was observed under an inverted phase-contrast tissue culture microscope after $48 \mathrm{~h}$ of treatment with NS and AQD and observations were recorded as a microscopic image. A change in the morphology of cells, like rounding or shrinking, vacuolization, and granulation in the cell cytoplasm is an indication of cytotoxicity.

\section{2. 5. 12. Apoptosis Study by Fluorescent Microscopy using $\mathrm{Eb}$ (Ethidium Bromide) and $\mathrm{AO}$ \\ (Acridine Orange) Double Staining Method.}

The MCF-7 cells were washed using cold phosphate buffer saline solution (PBS) after treating them with different concentrations of NS and AQD as $13.2262 \mu \mathrm{g} / \mathrm{mL}$, $26.4524 \mu \mathrm{g} / \mathrm{mL}$ (LD 50 Concentration), $52.9048 \mu \mathrm{g} / \mathrm{mL}$ for forty-eight-hour, following $\mathrm{AO}(100 \mu \mathrm{g} / \mathrm{ml})$ and $\mathrm{EtBr}(100$ $\mu \mathrm{g} / \mathrm{ml}$ ) stains for $10 \mathrm{~min}$ at RT. Further, with $1 \mathrm{X}$ PBS solution the cells which are stained are washed twice and were observed under a fluorescent microscope using a blue filter (Zhang et al., 1998). Based on staining reactions, the cells were grouped as normal green nucleus (living cells), bright green colored nucleus with fragmented or condensed chromatin (early apoptotic), orange-colored nuclei with condensation or fragmentation of chromatin (late apoptotic), and uniformly orange-stained cell nuclei (necrotic cells).

\section{2. 5. 13. Pharmacokinetic and Biodistribution Study in Rats}

Sprague- Dawley rats (mean weight 200-220 g) were purchased from Global Bioresearch Solutions Pvt. Ltd., Pune. The pharmacokinetic (PK) and biodistribution studies of MTX were performed using the Sprague- Dawley rats model (BVCPK / CPCSEA /IAEC / 01/14/20172020). Initially, rats were kept on fast overnight with free access to water ad libitum. For the study, rats were randomly divided into three groups $(n=3)$. Group I was selected as the test group (MTX-NS), the standard group (group II) was treated with MTX-AQD, and group III (control group) was given a normal saline solution. On the day of the study, the rats have been dosed $(40 \mathrm{mg} / \mathrm{kg})$ with optimized MTX-NS and MTX-AQD via oral feeding cannula. Blood samples $(0.5 \mathrm{~mL})$ were obtained from the retro-orbital vein at predetermined intervals of $0,2,3,4,6$, $12,24,36,48$ hours under mild anesthesia and transferred into a tube containing EDTA. Finally, blood samples were centrifuged immediately at $3,000 \mathrm{rpm}$ for $10 \mathrm{~min}$ at $4{ }^{\circ} \mathrm{C}$, and separated plasma and samples were stored at $-20{ }^{\circ} \mathrm{C}$. The rats were sacrificed $(n=3)$ using the cervical dislocation method. The distribution of the drug in vital organs is measured after $72 \mathrm{~h}$ of dosing. Spleen, liver, heart, brain, lungs, stomach, and kidney tissue samples were homoge-

$$
\text { Growth inhibition }(\%)=1-\frac{\text { Mean OD of the test compound }}{\text { Mean OD at untreated cells }} X 100
$$


nized and centrifuged to get clear tissue samples, further stored at $-20{ }^{\circ} \mathrm{C}$.

Plasma and tissue sample preparation: The tissue and plasma blood samples have been combined with $20 \mu \mathrm{L}$ (MTX) solution $(5 \mu \mathrm{g} / \mathrm{mL})$ and deproteinization of the sample was achieved by applying $100 \mu \mathrm{L}$ acetonitrile to a $50 \mu \mathrm{L}$ plasma sample and $300 \mu \mathrm{L}$ acetonitrile to $200 \mu \mathrm{L}$ of clear homogenates of tissue followed by cold centrifugation $(6,000 \mathrm{rpm}, 15 \mathrm{~min})$ at $4{ }^{\circ} \mathrm{C}$. The collected transparent supernatant was filtered by a syringe filter $(0.20 \mu \mathrm{m})$ and injected into the HPLC for the determination of MTX content in tissue and blood samples. ${ }^{23,27}$

\section{2. 5. 14. Pharmacokinetic Analysis}

A non-compartmental model was used to perform the PK study of the plasma concentration-time profile using Microsoft Excel (Microsoft office 2016). PK parameters obtained directly from plasma data, includes $\mathrm{AUC}_{0-\mathrm{t}}$ (AU plasma concentration-time curves), $\mathrm{T}_{\max }$ (the time to reach maximum plasma concentration), $\mathrm{C}_{\max }$ (maximum plasma concentration), $\mathrm{K}_{\mathrm{el}}$ (elimination rate constant), $\mathrm{t}_{1 / 2}$ (elimination halflife), $\mathrm{Cl}$ (clearance), VD (volume of distribution), MRT (mean residence time), and $\mathrm{F}_{\text {rel }}$ (relative bioavailability). Lyophilized

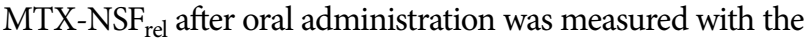
$\mathrm{AQD}$ as a reference using the following formula (Equation 5).

$$
\mathrm{F}_{\text {rel }}=\frac{\mathrm{AUC} \text { test }}{\mathrm{AUC} \text { reference }} \times 100
$$

All data were revealed as \pm SD (mean) and the level of significance was taken as $\mathrm{P}<0.05^{22}$. While the Absolute bioavailability $(\mathrm{F} \%)$ is calculated by comparing exposure of drug by extra vascular route of MTX NS to its i.v. an administration which is assumed to be $100 \%$. It is calculated by the given formula (equation 6):

$$
F \%=\frac{A U C_{e . v .}}{A U C_{i . v .}} \times \frac{\text { Dose }_{i . v .}}{\text { Dose }_{e . v .}} \times 100
$$

\section{2. 5. 15. HPLC Analysis of MTX}

The MTX content was analyzed through reverse-phase (RP)- HPLC (UV detector system, intelligent HPLC pump, Model Jasco PU-2080) using a reverse-phase C18 column (5 $\mu \mathrm{m}$ pore size, $150 \times 4.6 \mathrm{~mm}$, Phenomenex $)$. The optimized mobile phase was $(70: 30 \mathrm{v} / \mathrm{v})$ water and acetonitrile mixture. For separation, HPLC analysis was performed using a constant flow rate $(1.0 \mathrm{~mL} / \mathrm{min})$, with a $20 \mu \mathrm{L}$ injection at 25 ${ }^{\circ} \mathrm{C}$ column temperature, and $303 \mathrm{~nm}$ wavelengths under isocratic conditions. The curve of calibration for MTX in plasma was found within the linear concentration range of $15-100 \mu \mathrm{g} / \mathrm{mL}\left(\mathrm{R}^{2}=0.9865\right)$ with pazopanib as an internal standard. The experimental outcomes indicate a mean \pm SD and $<0.05$ level of significance.

\section{2. 5. 16. Stability Studies}

The stability studies of optimized lyophilized MTXNS and liquid MTX-NS were performed [ICH Q1A (R2)].
In brief, the developed formulations were wrapped into aluminum foils and stored in a refrigerator at $4{ }^{\circ} \mathrm{C}$, room temperature, and $40^{\circ} \pm 2{ }^{\circ} \mathrm{C} / 75 \pm 5 \%$ relative humidity (in the stability chamber) for 6 months. As per the defined time interval, the DC and particle size were calculated to check the chemical as well as physical stability of developed MTX-NS. ${ }^{11}$

\section{2. 17. Statistical Analysis}

The outcomes of the study were analyzed using ANOVA, multilinear regression analysis, and lack-of-fit tests. Student's t-test where appropriate, was used and expressed as mean $\pm S D(n=3)$, to test the statistical significance. ${ }^{11}$

\section{Results and Discussion}

\section{1. Screening of the Stabilizer for MTX-NS}

\section{1. 1. Suspending Effect of Stabilizers on MTX}

In the development of NS, stabilizers and polymers play a crucial role. A lack of adequate stabilizers causes aggregation of nano-sized drug particles due to extremely free of surface energy. An admirable stabilizer efficiently decreases the nanoparticle's surface energy by dispersing them at a water and particle interface to avoid particulate accumulation in the NS. Moreover, the ionic/steric barrier is therefore stopped from Ostwald's ripening. A stable MTX-NS system with a suitable stabilizer was optimized by various factors such as sedimentation effect, suspending effects, and particle size analysis (Table S5). ${ }^{18,28}$

The combination of poloxamer 188 / tween $80 /$ SLS $(198.87 \pm 0.01 \mu \mathrm{g} / \mathrm{ml})$ presented superior suspending effect on MTX, followed by poloxamer $188(126 \pm 0.05 \mu \mathrm{g} /$ $\mathrm{ml})$, ween $80(119.14 \pm 0.04 \mu \mathrm{g} / \mathrm{ml})$, and SLS ( $112.83 \pm$ $0.05 \mu \mathrm{g} / \mathrm{ml}$ ). While the particle size of the formulation prepared by poloxamer 188 / tween $80 /$ SLS, poloxamer 188 , tween 80 , and SLS was found to be $332.45 \pm 1.03$, $293.46 \pm 3.32,301.65 \pm 1.45$, and $349.09 \pm 2.18 \mathrm{~nm}$ respectively. Poloxamer 188, tween 80 , and SLS did not produce stratification and sedimentation. The high surface free energy of nanosized particles makes NS a highly unstable thermodynamic system. Thus, to optimize the surfactant and stabilizer system and to stabilize the nanosuspension, the CCD response surface was designed to finalize the surfactant and their concentration from the above results, with the highest electric repulsions.

\section{1. 2. Molecular Docking}

The interactions between MTX and stabilizers show that stabilizers can solubilize drugs to improve their stability in the present study. Figure 1 shows the virtual interaction between MTX and stabilizers. In this study, the MTX and stabilizers lead to strong interaction by using less 
binding energy with strong hydrogen, hydrophobic, and Vander Waal interactions. This means that stronger hydrogen bonding between the MTX and stabilizers like Poloxamer 188 and Tween 80 can virtually improve the stability and solubility of MTX.

\section{3. Quality by Design}

\section{3. 1. Risk Assessment}

For identification of possible risks of process and formulation variables on the CQAs, viz., DC, EE, and particle

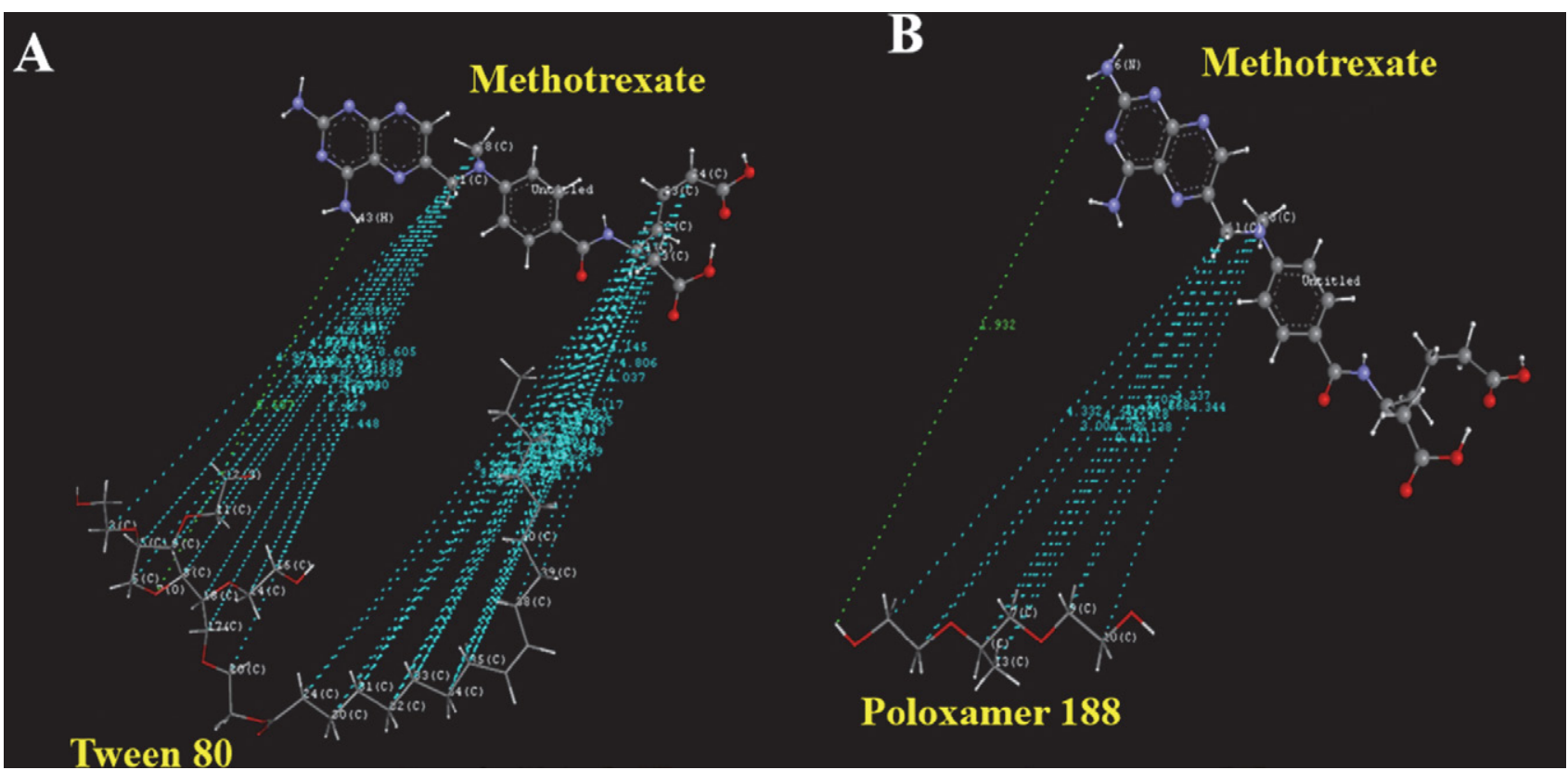

Figure 1. Docking study: a) interaction of MTX with Poloxamer 188, b) interaction of MTX with tween $80 .{ }^{*}$ Colour code Light blue: Vander Waal interaction, Green: Hydrogen bonding

\section{2. Process Analytical Technology (PAT): - Particle Analysis, \%EE, and DC}

MTX-NS was developed using Tween 80 as a stabilizer and Poloxamer 188 as polymers with the applications of the QbD. ${ }^{17}$ As a result of the PAT study, the particle size, $\mathrm{EE}$, and DC of the developed NS were found to be in the range of $239.30-309.60 \mathrm{~nm}, 99.42-99.96 \%$, and $87.56-$ $88.32 \%$ respectively.

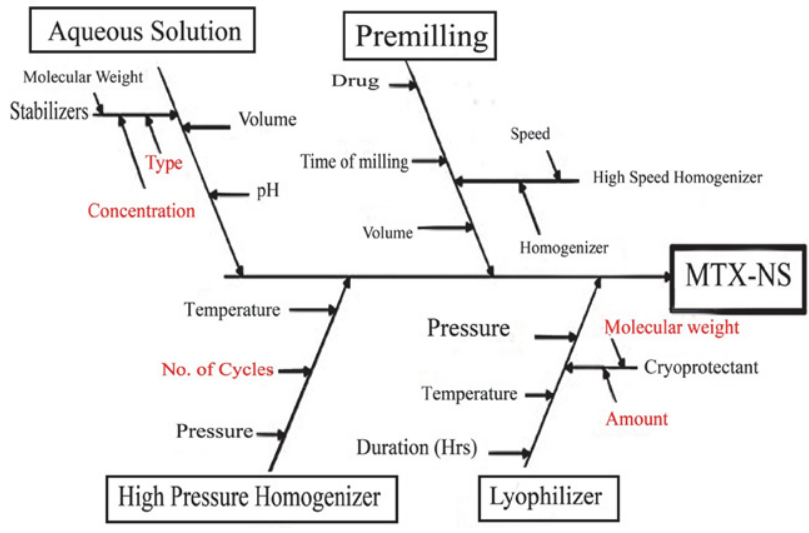

Figure 2. Ishikawa Diagram illustrating process and formulation variables that may have an influence on the properties of MTX-NS size of MTX-NS an Ishikawa diagram was established (Figure 2). As a result of risk analysis, the 8 possible risk factors were identified based on preliminary experiments and prior knowledge and were further evaluated using experimental designs. ${ }^{11}$

\section{3. 2. Plackett-Burman Design}

$\mathrm{PB}$ design is carried out by introducing 8 factors, at 2 levels, with 12 runs to screen the significant formulation and process variables for the development of MTX-NS. The formulations were piloted and the resulting response values are listed in Table 3. The significant and most contributing factors for the first response i.e. particle size (Y1) were the speed of homogenizer (X1, pre-NS), the concentration of tween $80(\mathrm{X} 7)$, and the concentration of poloxamer (X5) respectively (Table 4 ). The value of $\mathrm{R}^{2}$ found was 0.8990 , which indicates a significant model fitting of the tested model. From ANOVA the p-value for main effects obtained was 0.1750 , which was not statistically significant. Hence, by using CCD most significant factors were further evaluated. The particle size plays a crucial role for MTX-NS as they affect the stability, drug release, bioavailability and biodistribution, and cellular uptake of drugs.

Following polynomial equation 7 can describe Y1, 
Table 3. Plackett-Burman experimental design matrix with observed values of response variables.

\begin{tabular}{|c|c|c|c|c|c|c|c|c|c|c|}
\hline $\begin{array}{l}\text { Batch } \\
\text { code }\end{array}$ & $\begin{array}{c}\mathrm{X1} \\
(\mathrm{rpm})\end{array}$ & $\begin{array}{c}\mathrm{X} 2 \\
(\mathrm{~min} .)\end{array}$ & $\begin{array}{c}\mathrm{X3} \\
\left(\text { Bars }^{\star} 1000\right)\end{array}$ & $\mathrm{X} 4$ & $\begin{array}{c}\text { X5 } \\
(\mathrm{mg})\end{array}$ & $\begin{array}{c}\text { X6 } \\
(\mathrm{mg})\end{array}$ & $\begin{array}{c}\text { X7 } \\
(\mathrm{mg})\end{array}$ & $\begin{array}{c}\text { X8 } \\
(\mathbf{m g})\end{array}$ & $\begin{array}{l}\mathrm{Y} 1^{\star} \\
(\mathbf{n m})\end{array}$ & $\begin{array}{l}Y^{*} \\
(\%)\end{array}$ \\
\hline 1 & 1 & -1 & 1 & 1 & -1 & 1 & 1 & 1 & $141 \pm 0.12$ & $76.13 \pm 0.16$ \\
\hline 2 & -1 & -1 & -1 & -1 & -1 & -1 & -1 & -1 & $208 \pm 0.10$ & $73.55 \pm 0.19$ \\
\hline 3 & -1 & -1 & -1 & 1 & -1 & 1 & 1 & -1 & $167 \pm 0.22$ & $64.36 \pm 0.13$ \\
\hline 4 & -1 & -1 & 1 & -1 & 1 & 1 & -1 & 1 & $215 \pm 0.15$ & $74.63 \pm 0.11$ \\
\hline 5 & -1 & 1 & -1 & 1 & 1 & -1 & 1 & 1 & $152 \pm 0.11$ & $92.56 \pm 0.17$ \\
\hline 6 & -1 & 1 & 1 & 1 & -1 & -1 & -1 & 1 & $228 \pm 0.21$ & $77.13 \pm 0.19$ \\
\hline 7 & 1 & 1 & -1 & 1 & 1 & 1 & -1 & -1 & $188 \pm 0.19$ & $97.5 \pm 0.20$ \\
\hline 8 & 1 & 1 & 1 & -1 & -1 & -1 & 1 & -1 & $202 \pm 0.10$ & $69.28 \pm 0.22$ \\
\hline 9 & -1 & 1 & 1 & -1 & 1 & 1 & 1 & -1 & $199 \pm 0.13$ & $76.5 \pm 0.13$ \\
\hline 10 & 1 & 1 & -1 & -1 & -1 & 1 & -1 & 1 & $151 \pm 0.16$ & $76.5 \pm 0.15$ \\
\hline 11 & 1 & -1 & -1 & -1 & 1 & -1 & 1 & 1 & $175 \pm 0.21$ & $72.92 \pm 0.17$ \\
\hline 12 & 1 & -1 & 1 & 1 & 1 & -1 & -1 & -1 & $220 \pm 0.24$ & $67.98 \pm 0.12^{*}$ \\
\hline
\end{tabular}

Mean $\pm \operatorname{SD}(n=3)$.

Table 4. ANOVA analysis for response variables in Plackett - Burman design matrix

\begin{tabular}{|c|c|c|c|c|c|c|}
\hline & & \multirow[t]{2}{*}{ Factors } & \multicolumn{2}{|c|}{ Y1: Particle size (nm) } & \multicolumn{2}{|c|}{ Y2: Drug content (\%) } \\
\hline & & & $p$ value & $\%$ Contribution & p value & $\%$ Contribution \\
\hline$\beta_{0}$ & : & Constant & 0.1750 & - & 0.2884 & - \\
\hline A & : & Speed of homogenizer ${ }^{*}(\mathrm{rpm})$ & 0.0715 & 25.23 & 0.1953 & 13.78 \\
\hline B & : & Time of homogenizer ${ }^{*}(\mathrm{~min})$. & 0.8133 & 0.22 & 0.1761 & 15.52 \\
\hline $\mathrm{C}$ & : & Homogenization pressure ${ }^{\star}\left(\operatorname{Bar}^{\star} 1000\right)$ & 0.8591 & 0.13 & 0.3962 & 4.87 \\
\hline $\mathrm{D}$ & : & Number of cycles & 0.5473 & 1.54 & 0.1283 & 21.72 \\
\hline $\mathrm{E}$ & : & Concentration of Poloxamer 188 (mg) & 0.0550 & 31.52 & 0.1339 & 20.80 \\
\hline $\mathrm{F}$ & $:$ & Concentration of SLS $(\mathrm{mg})$ & 0.5473 & 1.54 & 0.5495 & 2.26 \\
\hline G & : & Concentration of Tween $80(\mathrm{mg})$ & 0.0594 & 29.56 & 0.4109 & 4.53 \\
\hline $\mathrm{H}$ & $:$ & Concentration of Methotrexate $^{*}(\mathrm{mg})$ & 0.8361 & 0.17 & 0.6175 & 1.54 \\
\hline
\end{tabular}

Particle size $=+187.17-14.17^{\star} \mathrm{A}+1.33^{\star} \mathrm{B}-1.00^{\star} \mathrm{C}+3.50^{\star} \mathrm{D}-15.83^{\star} \mathrm{E}+3.50^{\star} \mathrm{F}+15.33^{\star} \mathrm{G}-1.17^{\star} \mathrm{H}$

The equation represents, with an increase in the concentration of SLS and concentration of tween 80 , there is an increase in average particle size, while increasing the concentration of poloxamer 188, decreases the average particle size (Y1). Particle size also decreases with an increasing speed of homogenizer and pressure of high-pressure homogenizer, with increasing MTX concentration. The decreased size of particles is also seen with the increasing time of homogenizer and the number of cycles of ber of cycles (X4), and the concentration of poloxamer 188 (X5), respectively (Table 1 ). The $\mathrm{R}^{2}$ value was 0.8502 indicating a significant fit for the model being tested. From ANOVA the $p$-value for main effects obtained was 0.2884 , which was not statistically significant. Hence, CCD was used for further significant factors evaluation. DC has a chief part in a therapeutic activity at a given dose of MTX in NS.

Following polynomial equation 8 describes Y2,

$$
\mathrm{DC}=+86.58+2.18^{\star} \mathrm{A}+2.31^{\star} \mathrm{B}-1.30^{\star} \mathrm{C}+2.74^{\star} \mathrm{D}-2.67^{\star} \mathrm{E}-0.88^{\star} \mathrm{F}-1.25^{\star} \mathrm{G}+0.73^{\star} \mathrm{H}
$$

$\mathrm{HPH}$. Thus, from all the process variables, the percentage contribution for average particle size is a concentration of tween $80(29.56 \%)$, the concentration of poloxamer 188 $(31.52 \%)$, and the speed of homogenizer $(25.23 \%)$, respectively. The smallest particle of $141 \mathrm{~nm}$ could be achieved by experimenting using $0.5 \mathrm{~mL}$ of tween $80,75 \mathrm{mg}$ of poloxamer 188 at $8000 \mathrm{rpm}$ speed.

For the DC (Y2), the most contributed and significant factors were the time of homogenizer (X2), the num-
Polynomial equation 8 represents that, DC (Y2) was increased with increasing concentration of MTX and speed of homogenizer, while it decreases with an increasing concentration of poloxamer 188, SLS, and tween 80 , respectively. It also increases with an increasing number of HPH cycles and the time of homogenizer. DC also decreases with the increasing pressure of HPH. From all the process variables, the $\%$ contribution of a time of homogenizer (15.52\%), number of cycles (21.72\%), and concentra- 
tion of poloxamer 188 (20.80\%) influence DC, respectively. Thus, achieving $97.50 \%$ of DC in MTX-NS could be achieved by experimenting using $50 \mathrm{mg}$ of poloxamer 188 for 45 min homogenization at 25 cycles of $\mathrm{HPH}$.

\section{3. 3. Optimization of MTX-NS by Central Composite Design}

\subsection{1. Model Fitting}

By design of expert (DOE), 20 runs were proposed and the input of predicted and observed values for Y1, and Y2, responses range from 229.3 to $300.6 \mathrm{~nm}$, and 85.56 to $89.43 \%$, respectively (Table 5). Using DOE software, the obtained responses were fitted to cubic, 2FI, quadratic and linear models (Table S6). As the $\mathrm{R}^{2}$ values were greater than 0.9 , and both the predicted and observed values were less comparable with standard deviations (SD) $(<1.0 \%)$ and precision values, the best-fitted model for Y1, Y2, and Y3 were quadratic. ${ }^{25}$ As the ratios of maximum to minimum responses values were less than 10 , transformation is not necessary $(\mathrm{Y} 1=5.61 ; \mathrm{Y} 2=$ $2.46 ; \mathrm{Y} 3=8.22$ ).

\section{Effect on Size of Particle (Y1)}

The proposed polynomial equation 9 for particle size is as follows,

$$
\mathrm{Y} 1=+268.92+2.83(\mathrm{~A})-0.10(\mathrm{~B})-4.14(\mathrm{C})
$$

Where, Y1 is particle size, (A) concentration of tween 80 , (B) concentration of poloxamer 188, (C) number of cycles for MTX-NS formulation by HPH.

The $\mathrm{F}$ value was 2.89 , which demonstrated that the used model was significant. While their model terms were not significant as the Prob $>\mathrm{F}$ p-value is $<0.0567$, hence these models are used to develop the design space. The impact of independent factors on particle size was studied using $3 \mathrm{D}$ response surface plots. The $\mathrm{Y} 1$ responses predicted values range from 244.34 to $299.02 \mathrm{~nm}$. The positive value of the coefficient represents an increasing particle size. Figure $3 \mathrm{~A}$ and Figure S1, predicts that as the concentration of tween 80 (A) increases from 0.05 to $0.45 \mathrm{ml}$, the particle starts to aggregate. It may because of the saturation of surfactant in NS, as formed particles are adsorbed by an excess concentration of surfactant present in NS.

Table 5. CCD matrix with predicted and observed values of responses

\begin{tabular}{|c|c|c|c|c|c|c|c|}
\hline \multirow[b]{2}{*}{ Batch } & \multicolumn{3}{|c|}{ Independent variables } & \multicolumn{2}{|c|}{$\begin{array}{l}\text { Dependent variables } \\
\text { Observed values }\end{array}$} & \multicolumn{2}{|c|}{ Predicted values } \\
\hline & $\begin{array}{c}\mathrm{A} \\
(\mathrm{mg})\end{array}$ & $\begin{array}{c}\text { B } \\
(\mathrm{mg})\end{array}$ & $\mathrm{C}$ & $\begin{array}{c}\mathrm{Y} 1^{*} \\
(\mathrm{~nm})\end{array}$ & $\begin{array}{l}\mathrm{Y} 2^{*} \\
(\%)\end{array}$ & $\begin{array}{c}\mathrm{Y} 1 \\
(\mathrm{~nm})\end{array}$ & $\begin{array}{l}\text { Y2 } \\
(\%)\end{array}$ \\
\hline 1 & -1 & 1 & 1 & $280.60 \pm 0.10$ & $87.67 \pm 0.07$ & 280.09 & 86.85 \\
\hline 2 & 0 & 0 & 0 & $272.80 \pm 0.08$ & $88.64 \pm 0.11$ & 268.92 & 88.43 \\
\hline 3 & 0 & 0 & 0 & $270.30 \pm 0.03$ & $88.58 \pm 0.09$ & 268.92 & 88.43 \\
\hline 4 & 0 & 0 & 0 & $269.40 \pm 0.07$ & $88.13 \pm 0.06$ & 268.92 & 88.43 \\
\hline 5 & 0 & 0 & 1.68179 & $260.40 \pm 0.05$ & $86.80 \pm 0.04$ & 274.21 & 86.96 \\
\hline 6 & -1.68179 & 0 & 0 & $289.40 \pm 0.11$ & $85.89 \pm 0.08$ & 289.51 & 86.56 \\
\hline 7 & 1 & 1 & -1 & $278.20 \pm 0.09$ & $88.39 \pm 0.11$ & 281.22 & 86.85 \\
\hline 8 & 0 & 0 & 0 & $268.50 \pm 0.10$ & $88.12 \pm 0.1$ & 268.92 & 88.43 \\
\hline 9 & 0 & -1.68179 & 0 & $250.00 \pm 0.05$ & $86.32 \pm 0.06$ & 244.69 & 86.95 \\
\hline 10 & 1 & -1 & -1 & $300.60 \pm 0.06$ & $87.32 \pm 0.09$ & 294.22 & 86.95 \\
\hline 11 & 1 & -1 & 1 & $273.20 \pm 0.08$ & $89.43 \pm 0.11$ & 277.25 & 88.64 \\
\hline 12 & 1 & 1 & 1 & $275.40 \pm 0.12$ & $86.74 \pm 0.08$ & 252.95 & 86.76 \\
\hline 13 & 0 & 0 & 0 & $263.80 \pm 0.07$ & $88.96 \pm 0.12$ & 268.92 & 88.43 \\
\hline 14 & 0 & 0 & -1.68179 & $292.20 \pm 0.08$ & $85.26 \pm 0.09$ & 288.12 & 86.78 \\
\hline 15 & 0 & 0 & 0 & $270.40 \pm 0.06$ & $88.44 \pm 0.05$ & 268.92 & 88.43 \\
\hline 16 & -1 & -1 & 1 & $277.40 \pm 0.07$ & $85.62 \pm 0.06$ & 267.50 & 85.96 \\
\hline 17 & -1 & -1 & -1 & $240.20 \pm 0.10$ & $86.84 \pm 0.10$ & 255.77 & 85.63 \\
\hline 18 & -1 & 1 & -1 & $290.60 \pm 0.09$ & $88.73 \pm 0.09$ & 279.66 & 88.32 \\
\hline 19 & 1.68179 & 0 & 0 & $289.40 \pm 0.05$ & $86.57 \pm 0.11$ & 299.02 & 87.59 \\
\hline 20 & 0 & 1.68179 & 0 & $229.30 \pm 0.11$ & $86.56 \pm 0.09$ & 244.34 & 87.62 \\
\hline
\end{tabular}

${ }^{*} Y 1=$ Particle size $;{ }^{*} Y 2=$ Drug content $;{ }^{*} Y 3=$ Entrapment efficiency. ${ }^{*}$ Mean $\pm \mathrm{SD}(\mathrm{n}=3)$.

\section{3. 3. 2. Analysis of Response Surface Plots}

Response surface plots were extensively employed for the study of the interaction effects of selected factors on their responses and relationships. Thus, we have constructed a surface response plot for three responses ( $\mathrm{Y} 1$, and Y2), which are depicted in Figure 3.
When the concentration of poloxamer (B) increases from 25 to $105 \mathrm{mg}$ respectively, it prohibits the re-aggregation of dispersed particles leading to the existence of smaller bodies in NS. Further, it resulted in the decreased particle size of NS. The number of cycles (C) for HPH shows a direct relationship with particle size, with increased $\mathrm{C}$ the size of 
particle decreases. Effectively, the coefficient with a negative value is represented by decreasing particle size. An increase in the number of cycles leads to a reduction in the size of the particle of NS by increasing the viscosity of the system, which inhibits the Ostwald ripening. This is the reason for particle size reduction. Thus, it is a CQA and the factors i.e. concentration of poloxamer 188 and number of the cycle that affects particle size was optimized by CCD.

\section{Effect on DC (Y2)} follows,

The proposed polynomial equation 10 for DC is as

$\mathrm{Y} 2=+88.42+0.3055(\mathrm{~A})+0.1995(\mathrm{~B})+0.0560(\mathrm{C})$

The predicted $\mathrm{Y} 2$ response values range from 85.63 to $88.78 \%$. The design was not significant as the $\mathrm{F}$ value was 1.63 , while model terms were not significant as the
Prob $>\mathrm{F}$, a $p$-value is $<0.2292$, hence these models were not used to develop the design space. Here as ' $\mathrm{A}$ ' increases, there is an increase in DC. While the concentration of ' $\mathrm{B}$ ' shows an increasing effect on DC (Figure 3B and Figur S1). DC also increases with increasing ' $C$ '. The amount of drug i.e. dose present in nanoparticles is significant to study for the dissolution and pharmacokinetic parameters. However, DC had the most important effect on drug dissolution, which directly affects drug absorption and thus bioavailability.

\section{3. 4. Optimization Model Validation}

To achieve the predicted (software suggestions) composition, targeted criteria were fed into the software. The software-suggested values were selected as a region of interest based on desirability values and were practically used for their verification. The design expert software was
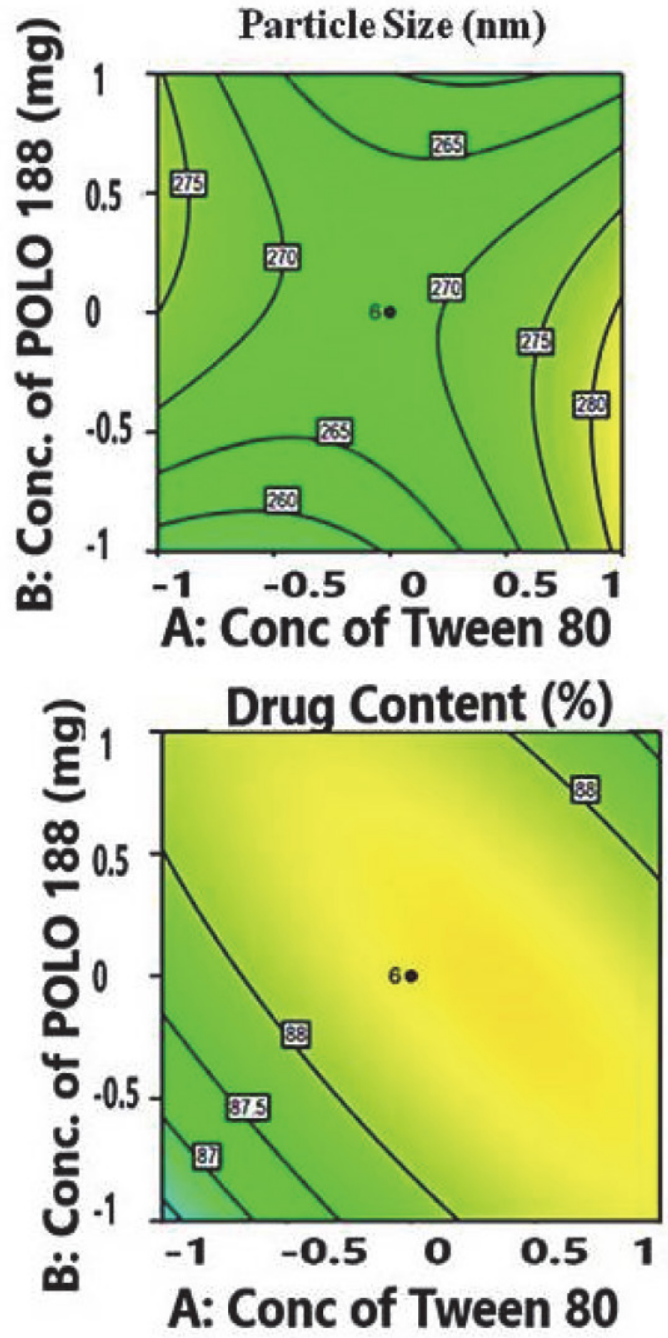

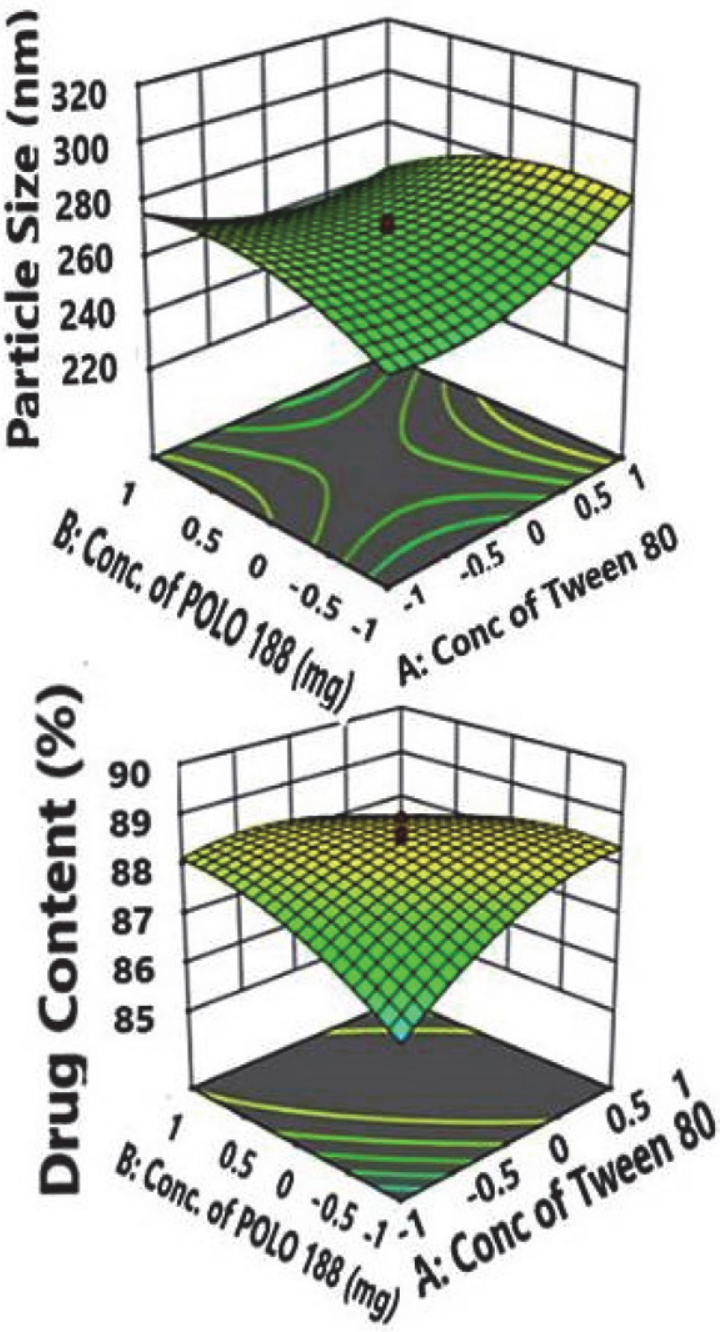

Figure 3. A) 3D surface response plot showing: a) The effect of factor A (Concentration of tween 80) and factor B (concentration of poloxamer 188) on response Y1 (particle size). B) The effect of factor A (Concentration of tween 80) and factor B (concentration of poloxamer 188) on response Y2 (drug content). C) The effect of factor A (Concentration of tween 80) and factor B (concentration of poloxamer 188) on response Y2 (drug content). 
used to statistically validate the obtained polynomials by ANOVA. The design space was constructed using a graphical method for this study. The desirability values based on selected software suggestions were observed as 1, providing $100 \%$ assurances to achieve the targeted product with efficient CPPs and CMAs (Table S7). Thus greater desirability value more possibility to gain the target product (Figure S2). The final formulation was prepared with optimized CPPs and CMAs, and its CQAs were analyzed. The predicted and actual results of CQAs were used to calculate the values of residuals to ensure the attainment of the design space. The calculation of residual values is also a verification/validation of the model and CQAs. The values of residuals were calculated as percent residual using the following formula: mulations. The MTX-NS3 was selected as an optimized MTX-NS formulation based on the data obtained from the two responses. Further, they were dried using Lyophilizer with $6 \%$ of mannitol as an optimized cryoprotectant to stabilize the system.

\section{3. 5. Particle Size and Zeta-potential Analysis}

MTX is a coarse micronized powder with fine texture, poor flow property, and aqueous solubility. The average particle diameter of pure MTX was $16.64 \pm 8.55, \mu \mathrm{m}$, indicating broad particle size distribution (PI: 0.945). The freshly prepared NS was lyophilized to enhance product stability. The lyophilized MTX-NS powder was smooth in appearance with a particle size of $260 \pm 0.25 \mathrm{~nm}$, respec-

$$
\text { Percent residual }=\frac{\text { Software suggested results- } \text { Actual obtained results }}{\text { Software suggested results }} \times 100
$$

The residuals were observed with very low values $(-1.27$ to -0.07$)$ which indicates that the obtained results with software predicted one has a very strong correlation. Residuals with lower values have more reproducibility and lesser variation of CQAs with the optimized CPPs and CMAs. The impact of concentration of tween 80 and concentration of poloxamer 188 (independent variables) was observed as more predominant from DOE results. The number of cycles favors the size of particles and the DC of MTX-NS. Thus to enhance the adaptability of the method, the number of cycles was fixed to 25 cycles and by using the remaining two factors the design space was developed. The overlay plot obtained from DOE software shows the design space to select the optimum tween 80 and poloxamer 188 concentrations to prepare highly stable NS with a lower size of particles (Figure S3). The three points that are located in the design space predict good responses. By changing the composition of factors ' $\mathrm{A}$ ' and ' $\mathrm{B}$ ' as per design space and keeping the number of cycles fix, three formulations, MTX-NS1, MTX-NS2, MTX-NS3 were developed and then characterized for three dependent variables. The plots constructed between observed and predicted responses showed a better relationship between the observed (actual) and theoretical (predicted) values for particle size (Y1), and DC (Y2) responses (Table 6). Negligible changes were seen in DC and particle size of MTX-NS1, MTX-NS2, and MTX-NS3 as compared to the above for- tively (Figure 4A) which was easily re-dispersed upon gentle shaking. The PDI represents size distribution and the potency of the measured average diameter of the drug components determined by the DLS system. Optimized lyophilized MTX-NS, showed, PDI values $0.212 \pm 0.33$, respectively indicating a narrow distribution of particle size. The lower PDI value indicates better stability of NS. Narrow and uniform particle size distribution favors dissolution enhancement, boosts intestinal absorption, and improves oral bioavailability.

Another important significant index is zeta potential, which directly affects the dispersion system stability, as it reflects steric or electrostatic barriers preventing agglomeration and aggregation of

nanoparticles. When drug particles possess very low values of zeta it provides appropriate steric or electric repulsion between each other, aggregation of particles is likely to occur. The zeta of reconstituted MTX-NS was found to be $-11.6 \pm 7.52 \mathrm{mV}$, which indicates the admirable physical stability of the developed nanosystem (Figure $4 \mathrm{~B}$ ).

\section{3. 6. Saturation Solubility Studies}

The saturation solubility (SS) studies of pure drug MTX with their optimized lyophilized formulations viz., MTX-NS was done using double distilled water. The SS of MTX-NS was $1487.23 \pm 0.064, \mu \mathrm{g} / \mathrm{ml}$, respectively. While

Table 6. Results of optimized batches obtained from an overlay plot of Design expert software

Optimized batchIndependent variablesDependent variables

\begin{tabular}{|c|c|c|c|c|c|c|c|c|}
\hline & \multirow[b]{2}{*}{ A } & \multirow[b]{2}{*}{ B } & \multirow[b]{2}{*}{$\mathrm{C}$} & \multicolumn{2}{|c|}{ Observed value } & \multicolumn{2}{|c|}{ Predicted value } & \multirow{2}{*}{$\begin{array}{c}\text { Zeta Potentia } \\
(\mathrm{mV})\end{array}$} \\
\hline & & & & Y1 (nm) & Y2 (\%) & Y1 (nm) & Y2 (\%) & \\
\hline MTX-NS1 & 0.12 & 75.8 & 25 & $271 \pm 0.32$ & $88.45 \pm 0.33$ & 272.43 & 88.23 & $-5.97 \pm 7.01$ \\
\hline MTX-NS2 & 0.13 & 74.2 & 25 & $267 \pm 0.24$ & $87.20 \pm 0.54$ & 266.16 & 87.80 & $-9.06 \pm 6.19$ \\
\hline MTX-NS3 & 0.10 & 76 & 25 & $260 \pm 0.25$ & $88.65 \pm 0.24$ & 259.71 & 87.35 & $-11.6 \pm 7.52$ \\
\hline
\end{tabular}

${ }^{*}$ Mean \pm SD $(n=3)$. 

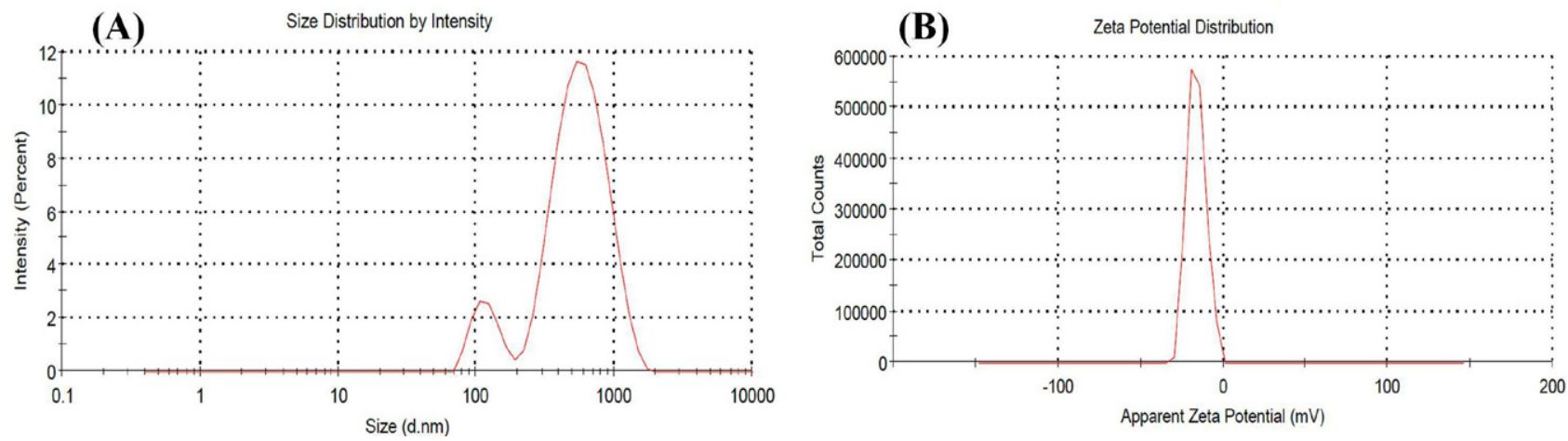

Figure 4. A) Average particle size for optimized batch MTX-NS. B] Zeta potential for MTX-NS optimized batch

for coarse MTX, the SS was $178.96 \pm 0.02 \mu \mathrm{g} / \mathrm{ml}$. Here the SS of MTX, in NS form is increased by 8.31 folds. This is because of the decreased size of particles and the enhanced surface area of NS as compared to pure drugs. Ostwald Freundlich equation states that decreasing particle size increases saturation solubility $(\mathrm{Cs})$

$$
\frac{\log \mathrm{Cs}}{\mathrm{C}}=\frac{2 \mathrm{sV}}{2.303 \mathrm{RT} r_{1} \mathrm{r}}
$$

Where, $\mathrm{s}=$ substance interfacial tension, $\mathrm{R}=$ gas constant, $\mathrm{C}=$ solids solubility with large particles, $\mathrm{r}_{1}=$ density of the solid, $C s=$ solubility, $r=$ radius, $V=$ particle molar volume, and $\mathrm{T}=$ absolute temperature. Another reason that increases saturation solubility is explained by the Kelvin equation, which suggests that with increased curvature the dissolution pressure increases with decreasing particle size. The particle size when reduced to the nanometer range, the curvatures then formed are enormous.

\section{3. 7. Surface Topographical Studies}

\section{3. 7. 1. Scanning Electron Microscopy (SEM)}

SEM of MTX shown that the coarse MTX particles bear an average size of particle $16.64-17.5 \mu \mathrm{m}$ with broad size distribution and mostly composed of drug crystals that are fragmented (Figure $5 \mathrm{a}$ ). The SEM (Figure $5 \mathrm{~b}$ ) of optimized lyophilized MTX-NS showed that particles were discrete and aligned in intimate contact as fiber-like structures with an absence of agglomeration that may be assigned by the presence of a stabilizer. Thus, indicated that lyophilization avoids aggregation of particles. The NS had a porous surface and were found slightly elongated but not completely spherical. These pores may be developed because of solvent evaporation from the surface of MTXNS during lyophilization. Thus SEM confirms that the larger scaly particles of MTX were successfully converted to nearly elongated, smaller-sized nanoparticles with a smoother surface on size reduction. This concludes that the crystalline nature of MTX was lost during the fabrication of the MTX-NS. The obtained NS particles were readily redispersible. SEM analysis also revealed that stabilizer-drug interaction leads to a matrix structure that is different from pure drug SEM images. This means that drug molecules are completely dispersed in the surfactant structures leading to the formation of nanoparticles. After lyophilization, the size of the MTX-NS particle was increased to a lesser extent but smaller than MTX. SEM images of MTX-NS showed quasispherical spheres and the
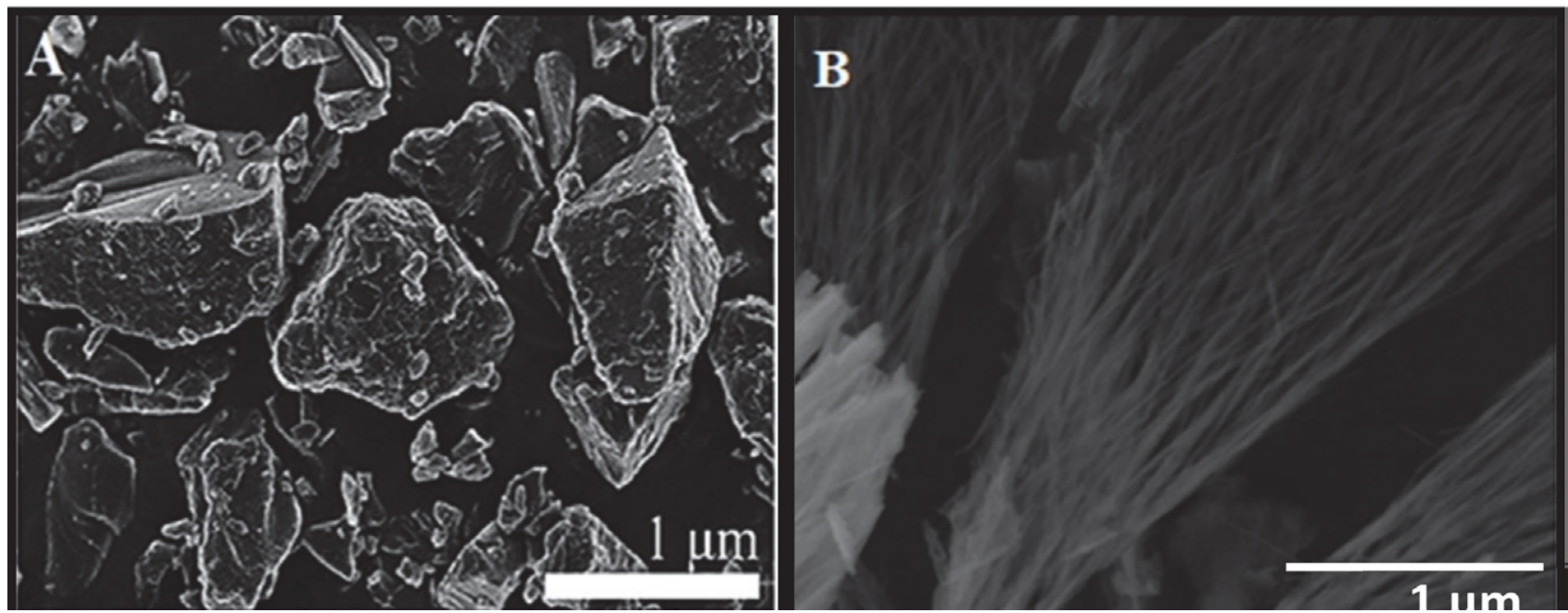

Figure 5 A) SEM images of pure MTX (B) Optimized MTX-NS 
size of the particle obtained was in correlation with the results of DLS.

\section{3. 8. Crystallographic Investigation}

\section{3. 8. 1. Differential Scanning Calorimetry (DSC)}

The stability and dissolution behavior of compounds are influenced by their crystalline state. During the $\mathrm{HPH}$ process, a high-energy input was generated because of the high powered density in the piston gap of the homogenizer. This increases the amorphous portion or complete amorphization of drug particles by changing their crystalline state. These extents of changes depend on applied pressure along with the physical hardness and chemical nature of the drug compound. Thermal analysis of MTX, physical mixtures of MTX, and optimized formulations were performed to study the differences in the solid state of MTX. The results of the DSC analysis are displayed in Figure 6. Coarse MTX powder showed a sharp distinct endothermic peak at $117.45{ }^{\circ} \mathrm{C}$, which was the marked intrinsic melting point peak of MTX, while DSC of the physical mixture was showed two distinct melting endotherm at $48.62{ }^{\circ} \mathrm{C}$ and $167.02{ }^{\circ} \mathrm{C}$, respectively. Whereas, the freeze-dried MTX-NS powder were recorded a sharp melting endotherm at $167.54{ }^{\circ} \mathrm{C}$ respectively.

The mannitol showed a sharp endothermic peak at $168.74^{\circ} \mathrm{C}$, which confirms the high crystalline nature of mannitol. The characteristic peak of MTX extinct in the thermogram of lyophilized optimized MTX-NS, and physical mixture. These changes are predicted because of the dilution effect of excipients on MTX, especially at a higher concentration of mannitol that had covered the MTX melting peak. Thus, the crystallinity of MTX disappeared or decreased because of its encapsulation by stabi-

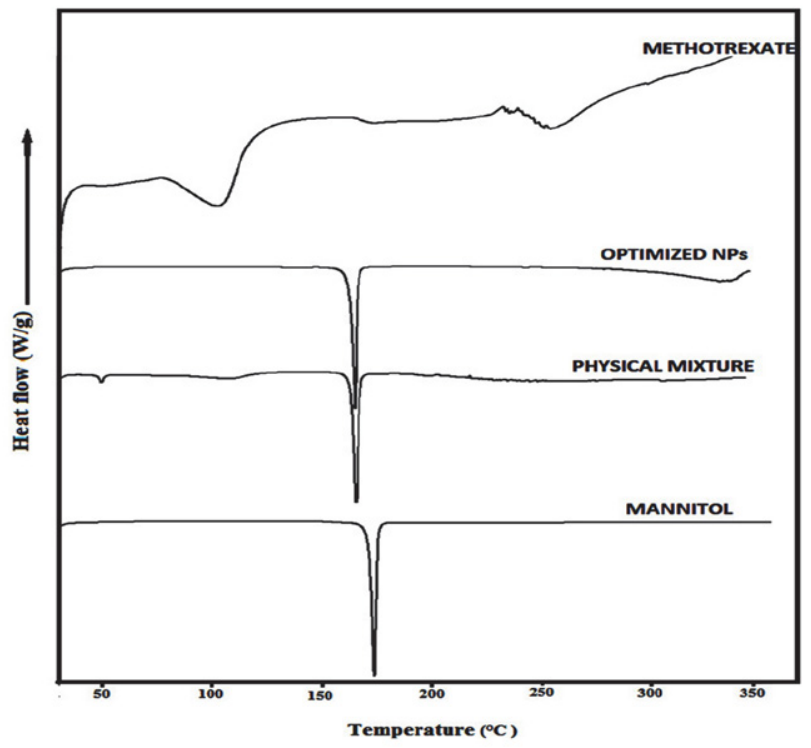

Figure 6. DSC Thermogram of A) Pure MTX B) Optimized MTXNS C) Physical mixture D) Mannitol lizers. The state of MTX in NS was not simply physically mixed but may exist as either amorphous or as molecular dispersion form in NS; these changes are because of the interactions between MTX, poloxamer 188, and tween 80 . Data obtained from DSC fails to explain factual changes that occurred in drug crystals during formulation processing. The results of the XRD analysis further confirmed the existing state of MTX loaded in MTX-NS.

\section{3. 8. 2. X-ray Powder Diffraction (XRPD)}

The crystalline state of lyophilized MTX-NS was confirmed by performing XRPD of coarse MTX powder, physical mixture, and optimized lyophilized MTX-NS. XRPD was used to analyze the probable changes in the physical nature of MTX-NS that occurred because of the development of a high-energy disintegration process. The chemical nature and physical hardness of the drug along with applied pressure are responsible for such changes. The XRPD patterns of powder MTX, physical mixtures, and optimized lyophilized MTX-NS are displayed in Figure 7. Sharp characteristic diffraction peaks were exhibited by MTX at $2 \theta$ of $7.58^{\circ}, 9.2^{\circ}, 11.42^{\circ}, 11.92^{\circ}, 12.82^{\circ}, 14.32^{\circ}, 15.38^{\circ}, 15.94^{\circ}$, $17.68^{\circ}, 19.36^{\circ}, 19.46^{\circ}, 21.38^{\circ}, 22.34^{\circ}, 24.18^{\circ}, 25.34^{\circ}, 24.16^{\circ}$, $26.06^{\circ}, 26.01^{\circ}, 26.96^{\circ}$ and $27.82^{\circ}$ and several short peaks between $2 \theta$ of $30.66^{\circ}$ and $80^{\circ}$, indicating its highly crystalline nature. The physical mixtures demonstrated reflections at $2 \theta$ of $9.44^{\circ}, 13.4^{\circ}, 17^{\circ}, 18.5^{\circ}, 20.12^{\circ}$, and $21.04^{\circ}$ with similar intensities as compared to MTX and higher intensities than MTX-NS. The physical mixture showed additional peaks similar to that of the parent crystalline compound.

Lyophilized MTX-NS showed four diffraction lines but at lesser intensities, as compared to MTX at $2 \theta$ of $9.62^{\circ}$, $13.6^{\circ}, 17.16^{\circ}, 19.8^{\circ}, 20.32^{\circ}, 21.26^{\circ}, 22.02^{\circ}, 24.62^{\circ}$ and $36.16^{\circ}$ with the additional peaks because of the presence of mannitol. In the PXRD spectra of lyophilized MTX-NS, the characteristic peaks of MTX were absent because of the dilution effect influenced by mannitol, without any qualitative variations in the diffractogram of MTX. This pattern revealed that the MTX-NS, were not completely amorphous in the state, hence the crystalline state of MTX and optimized lyophilized MTX-NS, were different, indicating the HPH technique, and lyophilization process did induce polymorphic transition or crystalline changes in the drug. Thus, amorphous form conversion enhances the solubility, thus enhances the rate of dissolution and the bioavailability of MTX. The state of MTX in NS was not simply physically mixed but may exist as either amorphous or as molecular dispersion form in NS, these changes are because of the interactions between MTX, poloxamer 188, and tween 80 . Moreover, the same induced properties and results were confirmed by previously mentioned studies.

\section{3. 9. FTIR}

FTIR provides information about the feasible molecular interactions between MTX and excipients used for the 


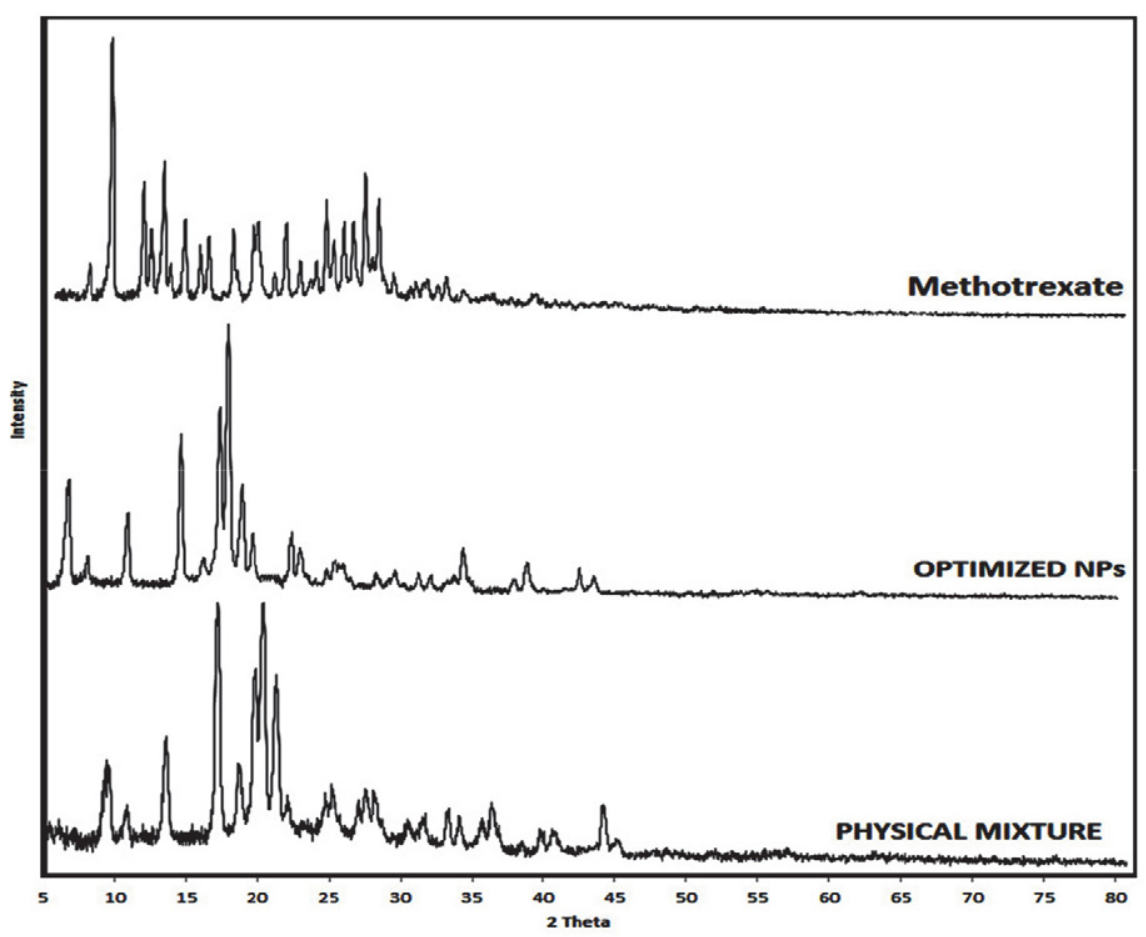

Figure 7. PXRD Spectra of A) Pure MTX B) Optimized MTX-NS C) Physical mixture

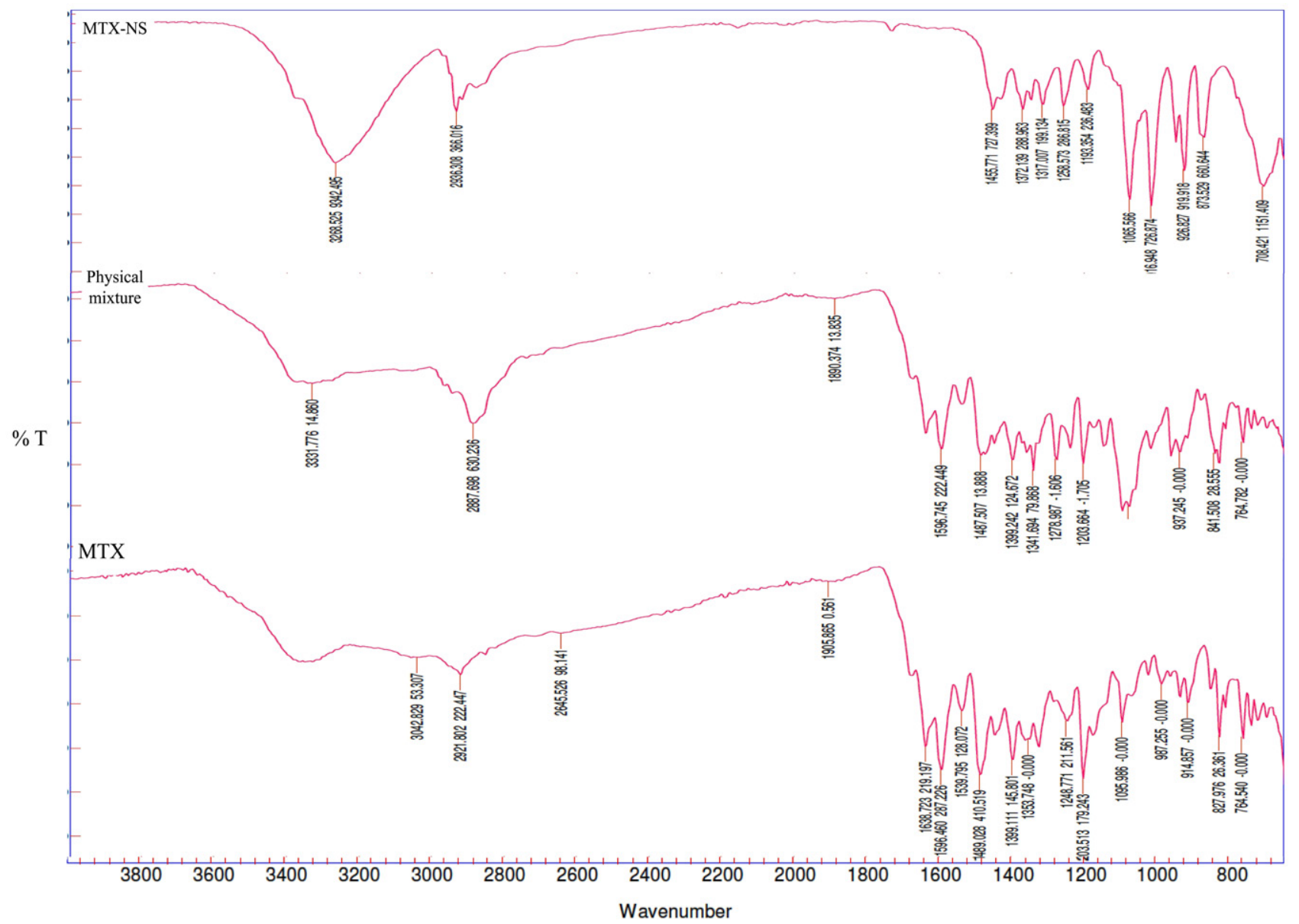

Figure 8. FTIR spectrum of A) pure MTX B) optimized NS(MTX-NS) and C) physical mixture 
development of formulation. The FTIR spectra of MTX coarse powder, physical mixture, and optimized lyophilized MTX-NS are disclosed in Figure 8. The FTIR spectra of MTX coarse powder revealed that the characteristic peaks at $1638.723 \mathrm{~cm}^{-1}, 1596.460 \mathrm{~cm}^{-1}, 1539.795$ $\mathrm{cm}^{-1}, 1203.513 \mathrm{~cm}^{-1}, 1489.028 \mathrm{~cm}^{-1,}$ and $1305 \mathrm{~cm}^{-1}$ had attributed to $\mathrm{C}=\mathrm{C}$ stretching and $\mathrm{O}-\mathrm{H}$ stretching and deformation. The FTIR spectra of MTX-NS show a broadening of peaks at $3268.52 \mathrm{~cm}^{-1}$ of $\mathrm{OH}$ bonding and $\mathrm{C}-\mathrm{H}$ stretching at $2936.308 \mathrm{~cm}^{-1}$ because of the diluting effect of mannitol or by $\mathrm{H}$ - bond formation between the poloxamer 188 and tween 80. An extra peak was observed in MTXNS at $1456.77 \mathrm{~cm}^{-1}$ that imputable because of the interaction between mannitol and excipients used for the development of MTX-NS. This showed that MTX was adsorbed onto the nanoparticle surface either by weak $\mathrm{H}$-bonding between the COO-groups of MTX and the $\mathrm{OH}$-groups of poloxamer 188 or by ionic bonds formed between the $\mathrm{NH}_{2}$ groups of MTX and the COO-groups present in mannitol and tween 80 . MTX has dispersed in the tween 80 and poloxamer 188 matrices in the microcrystalline form without polymorphic changes or transition into an amorphous form. Broadening at $708.421 \mathrm{~cm}^{-1}$ is because of the $\mathrm{H}$ - bond formation between the MTX and tween 80 . The absence of characteristics peaks of MTX at $1638.723 \mathrm{~cm}^{-1}$, $1596.460 \mathrm{~cm}^{-1}$, and $1489.028 \mathrm{~cm}^{-1}$ in MTX-NS is because of overlapping peaks of mannitol and tween 80 . Furthermore, the shifting of peaks to its lower wave number and broadening of characteristic peaks of MTX is seen in FTIR of MTX-NS, which is because of intermolecular $\mathrm{H}$ - bonding. While in the physical mixture all characteristic peaks of MTX were retained with the slight shifting of wavenumber. Because of physical interactions between different functional groups of the excipients and drugs, a weak hydrogen bond was formed. The physical interactions found here could be beneficial for the size and shape of the NS and their drug release pattern.

\section{3. 10. In-vitro Drug Release}

The dissolution behaviors of pure drug MTX, along with their optimized lyophilized formulations viz., MTXNS in SIF pH 6.8 is represented in Figure 9. The rate of MTX and MTX-NS dissolution was $28.575 \pm 0.021 \%$ and $99.27 \pm 0.04 \%$ within $60 \mathrm{~min}$ in SIF pH 6.8 respectively. The MTX-NS showed a dramatically enhanced rate of dissolution as compared to MTX coarse powder by 3.45 folds. Moreover, the MTX-NS displayed a marked increase in dissolution velocities, more than $70 \%$ as compared to MTX coarse powder (2.5\%) within $10 \mathrm{~min}$. These suggested that the profile of the dissolution of lyophilized MTXNS was distinctly superior as compared to MTX. As the size of MTX-NS particles was much smaller than that of MTX, it has a much larger surface area, hence a higher dissolution rate. Besides the particle size, the shape also plays a crucial role that may affect the dissolution of the drug. A particle that is irregular, flaky, and long may increase its average hydrodynamic thickness (h) at the boundary layer. Thus, the value of ' $h$ ' would be increased with decreased dissolution rate. The SEM image of MTX showed rodshaped particles in different sizes. Thus, concluded that enhancement in dissolution was because of the reduction in the size of the particle rather than shape alteration.

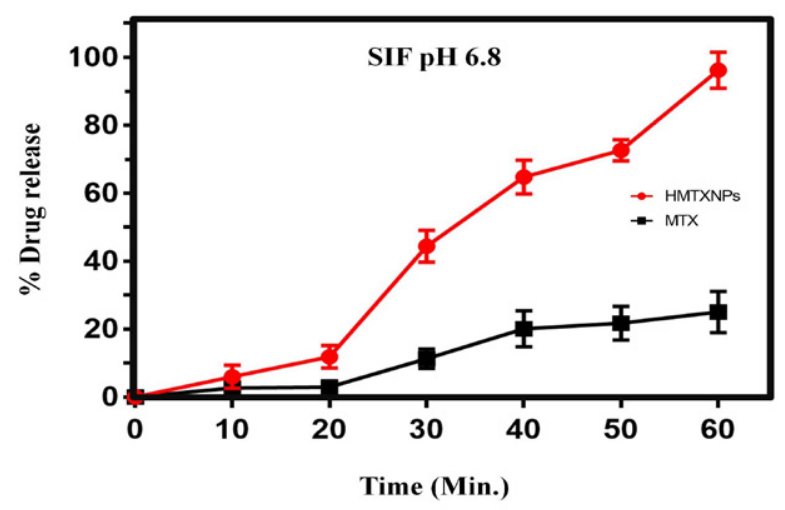

Figure 9. Dissolution profiles of optimized NS (MTX-NS) with a pure drug in simulated intestinal fluid (SIF) with $\mathrm{pH} 6.8$

\section{3. 11. Cytotoxicity Activity}

The MCF-7 breast cancer cells were cultured with MTX-NS, along with their aqueous dispersions (MTXAQD) to study the impact of drugs on cell proliferation of MCF-7. By MTT assay, the cell inhibition ratio was evaluated. The $\mathrm{IC}_{50}$ values were obtained by calculating non-linear regression values of the cytotoxicity data by using the sigmoidal dose-response equation with the help of Graph Pad Prism software 7. The obtained results show that the inhibition of MCF-7 cell growth by optimized MTX-NS was dose and time-dependent. However, significant inhibition of MCF-7 cell proliferation was observed when treated with the previously mentioned MTX-NS with a concentration above or at $6.25 \mu \mathrm{g} / \mathrm{mL}$. MTX-NS treated cells had a notable enhancement in growth inhibition rates as compared to MTX-AQD treated cells. These findings might be because of three possible aspects. First, the ability of MTX-NS to incarnate into cells by endocytosis or phagocytosis mechanism. Second, by increasing contact time and the area between drug and cells, as the smaller size NS initiates its adhesion to MCF-7 cells. As NS enhanced solubility and dissolution rates, it helps to induce sufficient molecular concentration of drugs around the cells. Thus, the MTX-NS was highly toxic to MCF-7 cells compared to free drugs. The values of $\mathrm{IC}_{50}$ of the MTX-NS solution were $27.73 \mu \mathrm{g} / \mathrm{mL}$. Whereas, the MTX-AQD was showed an $\mathrm{IC}_{50}$ value of about $59.56 \mu \mathrm{g} / \mathrm{mL}$ (Figure S4). The outcomes of this study indicated that the values of $\mathrm{IC}_{50}$ of NS are lower than MTX-AQD at the same incubation time (48 h). 


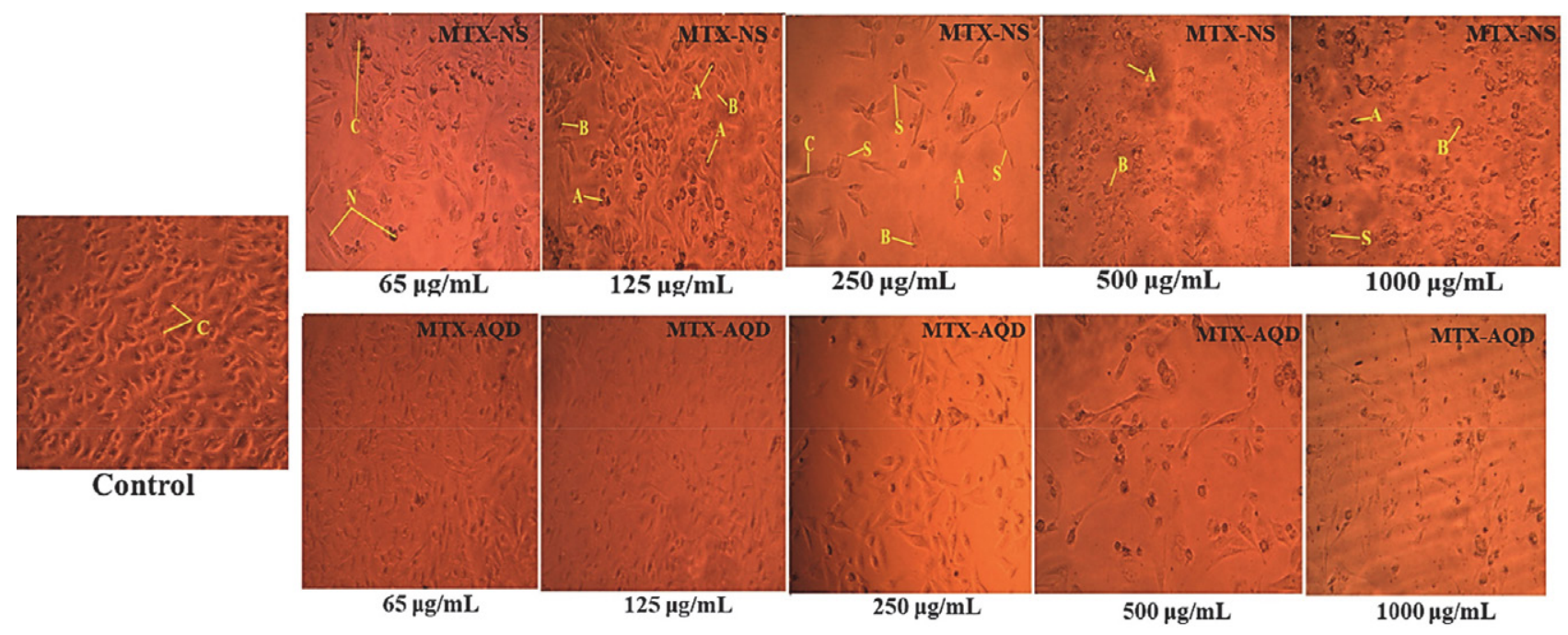

Figure 10. Photomicrographs (light microscopy; magnification, $\times 200$ ) showing morphological and growth inhibitory changes of MCF-7 cells following exposure to, MTX-NS for $48 \mathrm{~h}$

Noticeable morphological changes were seen in cells, which include membrane blebbing, nuclear fragmentation, and shrinkage of cells after exposure to MTX-NS and MTX-AQD for $48 \mathrm{~h}$. Further, more changes that are obvious were observed in NS treated cells as compared to untreated cells (control), Figure 10. [Control cells (C), Membrane blebbing (B), Condensed nuclei $(\mathrm{N})$, Cell shrinkage (C), Apoptotic bodies (A), Echinoid spikes (S \& E)]

\section{3. 12. Apoptosis Study on MCF-7 Cells}

Apoptosis study of MTX-NS by double staining method reveals the ability of drugs and especially the MTX to induce apoptosis. As displayed in Figure $11 \mathrm{~A}$, the green-colored nucleus indicates living cells in the control group, which are untreated. While Figure $11 \mathrm{~B}$ and $11 \mathrm{C}$ showed a decreasing ratio of living cells with increased concentration of AQD and NS. Herein, of AQD and NS $(12.5 \mu \mathrm{g} / \mathrm{mL})$ treated cells showed uniformly orangestained fluorescent nuclei but at a lesser amount as com- pared to NS treated cells, indicating necrosis of cells followed by the death of cells. The changed morphological of apoptosis cells, when treated with NS, include shrinkage of cells, followed by fragmentation and irregular shape. Such changes in morphology were observed in larger amounts with cells treated by NS as compared to AQD. Thus, the reduction in living cells of MCF-7 indicates an increase in the ratio of apoptotic cells.

\section{3. 13. Pharmacokinetic and Biodistribution Study in Wistar and Sprague-Dawley Rats}

To confirm the positive impact of NS on oral bioavailability enhancement of MTX in-vivo PK studies of NS and their AQD in rats were carried out and obtained results were correlated with each other. The mean concentration-time profile in the rat plasma for MTX is displayed in Figure 12, obtained when the single dose of $40 \mathrm{mg} / \mathrm{kg}$ of MTX was administered orally from NS and AQD and their PK parameters obtained are reported in Table 7 respective-

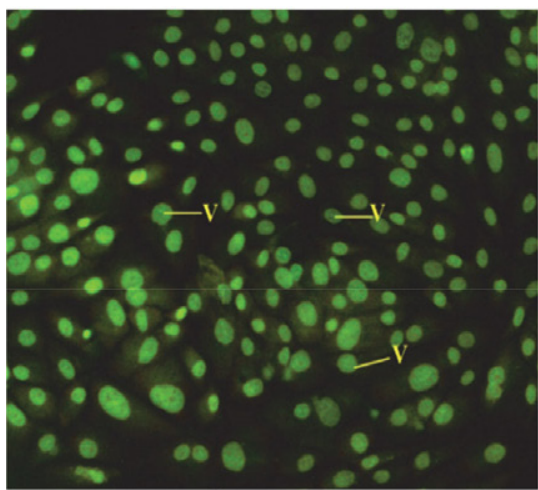

Control

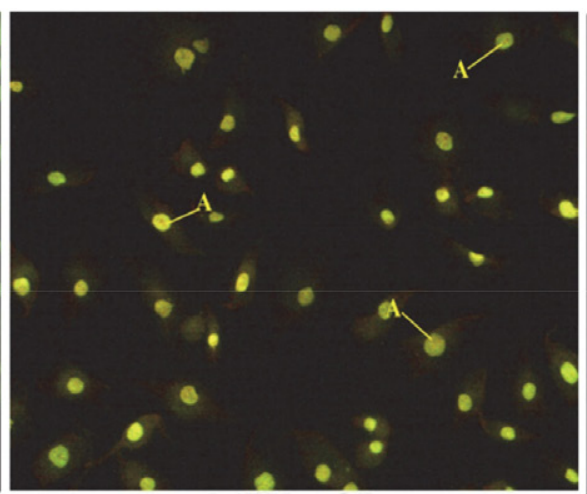

MTX-AQD

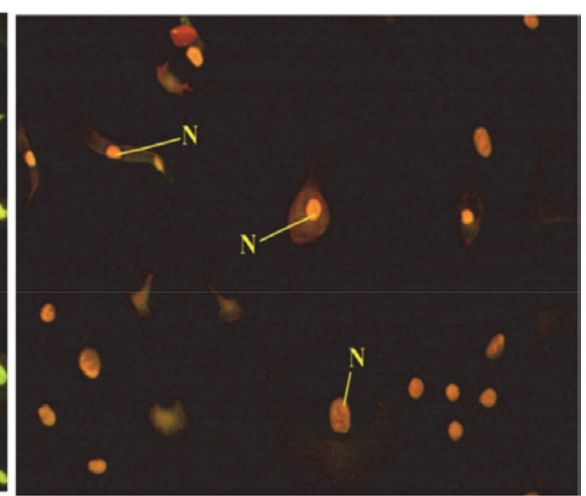

MTX-NS

Figure 11. Apoptosis study of MST-NS on MCF- $\&$ cells. A) Untreated cell lines that are intact and with green nucleus B) Cells treated with $25 \mu \mathrm{g} / \mathrm{ml}$ of AQD C) Cells treated with $25 \mu \mathrm{g} / \mathrm{ml}$ of NS; N-necrotic Cells, A- Apoptic cells, and V- Viable cells. 
ly. Following the oral administration of MTX-NS and MTX-AQD, the plasma concentration of MTX from MTX-NS in rats was significantly reached to a higher level than that of MTX-AQD at every time interval. The MTXNS exhibited higher $\mathrm{C}_{\max }$ and $\mathrm{T}_{\max }$, which indicates greater drug absorption but at a slower rate. The $\mathrm{C}_{\max }$ of MTX-NS increased by 2.53 folds. The reduced $\mathrm{C}_{\max }$ of MTX-AQD is because of the rapid distribution and metabolism of MTX. The coating of tween 80 and poloxamer 188 helps the circulation of formulation in the body for a prolonged period, thus $\mathrm{T}_{\max }$ of MTX-NS is higher than free MTX. The mean residence time (MRT) of MTX-NS and MTX-AQD was $27.61 \pm 2.10$ and $38.62 \pm 2.03$ hours, respectively. Thus, the $\mathrm{t}_{1 / 2}$ of MTX from MTX-NS was reduced to $\sim 8 \mathrm{~h}$, then free MTX, with $t_{1 / 2}$ of $18.78 \mathrm{~h}$. This drug is available in the body for a longer period in NS form for absorption. The relative and absolute bioavailability of MTX-NS was 8.83 fold high as compared to MTX-AQD. The area under the curve (AUC) is a vital PK parameter that explains the circulation and exposure time of the drug in bloodstreams. The AUC ${ }_{0-\mathrm{t}}$ of MTX-NS and MTX-AQD were $3932.79 \mu \mathrm{g} /$ $\mathrm{ml}{ }^{\star} \mathrm{h}$ and $445.39 \mu \mathrm{g} / \mathrm{ml}{ }^{\star} \mathrm{h}$, respectively. This increase in AUC indicated that the MTX oral absorption in rats was enhanced notably in lyophilized NS form.

Thus, the oral bioavailability of MTX was improved by decreased particle size, increased dissolution rate, and thus enhances membrane permeation of the drug. Here the size of MTX particle was reduced to nanometers from microscale. This significant reduction in the size of particles leads to tremendous enhancement in surface area which fastens the drug dissolution velocity as per NoyesWhitney equation. Moreover, reduction in the size of the particle improved the uptake of drugs not only by dissolution enhancement but also by other mechanisms like increased mucosal adhesion to GI surfaces that helps to prolong GI transit time and leads to efficient oral bioavailability. Thus, reduction in the size of the particle

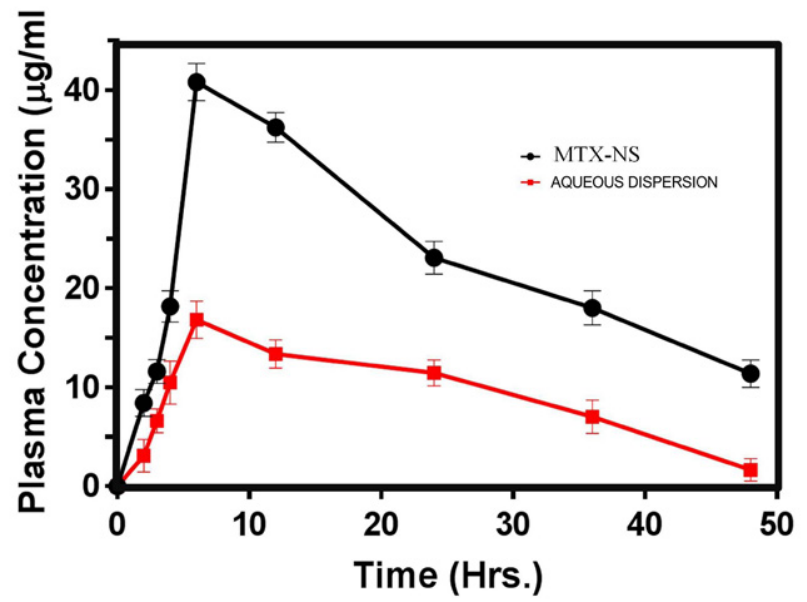

Figure 12. Plasma concentration-time profiles of MTX after oral intake of MTX-NS and the MTX-AQD formulation in rats. Each value represents the mean \pm S.D. $(n=3)$ and increased rates of drug dissolutions were the reason for higher $\mathrm{C}_{\max }$ and $\mathrm{AUC}_{0-\mathrm{t}}$ of MTX after oral administration. As a stabilizer moreover, poloxamer 188 has a thick coat on the surface of MTX-NS, which plays a chief role in bioavailability enhancement. It is an amphiphilic surfactant, that may enhance the MTX penetration ability and thus promote rapid permeation of the MTX nanoparticles through the intestinal epithelium, and finally into blood i.e. systemic circulation.

Table 7. Plasma pharmacokinetic parameters of MTX-AQD and Lyophilized MTX-NS in Sprague Dawley rats after oral administration

\begin{tabular}{|c|c|c|}
\hline $\begin{array}{l}\text { Pharmacokinetic } \\
\text { parameter }\end{array}$ & MTX-AQD & $\begin{array}{l}\text { Lyophilized } \\
\text { MTX-NS }\end{array}$ \\
\hline $\mathrm{C}_{\max }(\mu \mathrm{g} / \mathrm{ml})$ & $15.7 \pm 1.12$ & $39.70 \pm 1.32^{\star *}$ \\
\hline $\mathrm{T}_{\max }(\mathrm{h})$ & $5.00 \pm 1.59$ & $6.00 \pm 1.41^{\star *}$ \\
\hline $\mathrm{t}_{1 / 2}(\mathrm{~h})$ & $26.76 \pm 1.68$ & $18.78 \pm 1.36^{* *}$ \\
\hline MRT (h ) & $38.62 \pm 2.03$ & $27.61 \pm 2.10^{\star \star}$ \\
\hline $\operatorname{AUC}_{0-\mathrm{t}}\left(\mu \mathrm{g} / \mathrm{ml}{ }^{\star} \mathrm{h}\right)$ & $445.39 \pm 3.99$ & $3932.79 \pm 3.09^{\star *}$ \\
\hline $\operatorname{AUC}_{0-\infty}\left(\mu \mathrm{g} / \mathrm{ml}^{\star} \mathrm{h}\right)$ & $485.16 \pm 3.25$ & $6788.86 \pm 3.33^{\star *}$ \\
\hline $\mathrm{VD}(\mathrm{mL})$ & $109.24 \pm 2.22$ & $16.10 \pm 2.45^{\star \star}$ \\
\hline $\mathrm{Cl}\left(\mathrm{mL} \mathrm{h}^{-1}\right)$ & $2.83 \pm 2.24$ & $0.059 \pm 2.55^{\star \star}$ \\
\hline $\mathrm{KE}\left(\mathrm{h}^{-1}\right)$ & $0.026 \pm 2.15$ & $0.0037 \pm 2.35^{\star *}$ \\
\hline $\mathrm{F}_{\text {rel }}$ & - & $8.83 \pm 1.19$ \\
\hline $\mathrm{F} \%$ & 4.45 & 67.88 \\
\hline
\end{tabular}

After oral administration, the biodistribution study of MTX-NS and MTX-AQD showed a higher collection of MTX in the spleen, liver, stomach, and kidney (Figure S5). The liver is the major organ of the reticuloendothelial system (RES) that accumulates and metabolizes nanoparticles. The biodistribution data revealed the maximum concentration of MTX by liver, spleen, stomach, and kidney were $8.15 \pm 4.22,16.15 \pm 5.12,9.40 \pm 4.72$ and $4.73 \pm 5.12$ $\mu \mathrm{g} / \mathrm{g}$, for MTX-NS, respectively, after $72 \mathrm{~h}$ of oral administration. However, the MTX-AQD concentration in the liver, spleen, stomach, and kidney were $8.24 \pm 2.28,4.02 \pm$ $3.36,3.26 \pm 5.43$, and $2.45 \pm 3.22 \mu \mathrm{g} / \mathrm{g}$, respectively. This may be because of the faster elimination of MTX because of higher particle size as compared to MTX-NS. The higher uptake of MTX in the spleen, liver, and stomach is because of enhanced lymphatic uptake. After oral intake of MTX-NS, no weight loss, no systemic toxicity, or fatalities, or any other toxic effects were seen during the entire study in rats. The increased biodistribution of MTX-NS in the stomach as compared to MTX-AQD was maybe because of increased intimate contact of MTX with GIT absorptive cells because of increased surface area and adhesion properties of nanoparticles. Before the maceration, the stomach was cleaned for all waste or any food material to measure the levels of the stomach to the actual tissues. The concentration of MTX-NS in the brain was $5.03 \pm 4.21$ $\mu \mathrm{g} / \mathrm{g}$ and MTX-AQD was $1.56 \pm 4.18 \mu \mathrm{g} / \mathrm{g}$, which indicates 
that the MTX-NS can deliver MTX to the brain. Early studies suggest that the size of NS in a nanometer plays a key role to deliver the drug to the brain and it crosses the blood-brain barrier (BBB). Thus MTX-NS in lesser doses can be used to treat primary central nervous system lymphoma (PCNSL). The concentration of MTX in lungs and heart were $6.57 \pm 3.45$ and $4.05 \pm 3.25 \mu \mathrm{g} / \mathrm{g}$ for MTX-NS, while for MTX-AQD it was $2.00 \pm 4.62$ and $2.12 \pm 3.45$ $\mu \mathrm{g} / \mathrm{g}$ respectively. A comparison of MTX-AQD with MTXNS was not statistically significant $(\mathrm{p}>0.05)$. Thus, biodistribution studies conclude the accumulation of MTX-NS in the spleen, liver, stomach, and lungs in larger amounts as compared to the brain, lungs, and heart. ${ }^{11}$

\section{3. 14. Stability Studies}

The six-month stability data for lyophilized MTXNS with liquid MTX-NS are reported in Table 8. MTX-NS stored at room temperature showed an increased particle size from 260 to $365 \mathrm{~nm}$, within six months. While, storage under refrigerated conditions, showed there was a nominal increase from 260 to $300 \mathrm{~nm}$ indicating better stability under these conditions. The NS store at $40^{\circ} \pm 2{ }^{\circ} \mathrm{C} / 75 \pm 5 \%$ RH showed an increase in the size of particles from 260 to $388 \mathrm{~nm}$. Results conclude, temperature influences the aggregation of nanoparticles, thus the stability and aggregation were higher at RT and stability chamber as compared to refrigerator storage conditions for liquid NS. For liquid, MTX-NS particle size ranges from 260 to $300 \mathrm{~nm}$ for samples stored at the refrigerator that shows better stability of NS than other storage conditions (Table 8). The refrigerated condition does not have a significant effect on average particle size, whereas room temperature and stability chamber condition has a more deleterious effect. This concluded that higher temperature leads to greater particle aggregation which results in increased size of particles. Thus aggregation of particles at room temperature and stability chamber increases its particle size and thus they are less stable. Probably Ostwald ripening may be the second reason resulting in fluctuations at RT. The chemical stability results of formulation during various conditions of storage are featured in Table 8. Results suggest no signifi- cant change in the DC of MTX-NS and their lyophilized MTX-NS when stored at three storage conditions. Thus, it concluded that both the liquid and lyophilized MTX-NS are chemically stable at three storage conditions. Noteworthy, for physical stability of liquid NS, lyophilization, and storage at refrigerated conditions are recommended ${ }^{28}$.

\section{Conclusion}

Lyophilized MTX-NS was fabricated and characterized using the $\mathrm{QbD}$ approach to enhance solubility, bioavailability, and stability of MTX. To understand the impact of CMAs and CPPs on CQAs the QbD approach was applied. The main reason to use the $\mathrm{QbD}$ approach is to improve the quality and safety of NS formulation. By using the statistical experimental designs like PlackettBurman and Central Composite design within a QbD concept, the effect of process and formulation parameters which affects the CQAs of NS, and that influences the stability and solubility of MTX in NS were optimized. The particle size distribution of optimized MTX products from the CCD overlay plot showed an average particle size of $260 \pm 0.2 \mathrm{~nm}$, with a zeta potential of $-11.6 \pm$ $7.52 \mathrm{mV}$. The SEM and TEM studies conclude particles were spherical. The XRPD, FTIR, and DSC studies conclude the crystalline nature of MTX was intact in NS form, but there was a significant increase in dissolution velocity and release rate of MTX-NS, due to the reduced size of particles and larger surface area of MTX. The lyophilized NS was found to be stable in refrigerator storage conditions. The plasma pharmacokinetic parameters viz., $\mathrm{C}_{\max }, \mathrm{T}_{\max }, \mathrm{t}_{1 / 2}, \mathrm{AUC}_{\text {total, }}$ and MRT of NS on rats were significantly higher than MTX-AQD. The relative and absolute bioavailability of MTX-NS was enhanced by more than 8.83 folds. Higher MTX concentration was found in the liver within $72 \mathrm{hrs}$, concluded from the biodistribution study. In vitro cytotoxicity study proves the significant inhibitory effect of the MTX-NS against human breast cancer cells MCF-7 at a very low dose. Apoptosis studies conclude MTX-NS treated cells at a $12.5 \mu \mathrm{g} /$ $\mathrm{mL}$ concentration showed uniformly orange-stained flu-

Table 8. Physical stability data of lyophilized and liquid MTX-NS

\begin{tabular}{|c|c|c|c|c|c|c|c|c|c|}
\hline \multirow[t]{2}{*}{ Formulation } & \multirow{2}{*}{$\begin{array}{cc}\text { Storage } \\
\text { Temperature }\end{array}$} & \multirow{2}{*}{$\begin{array}{c}\begin{array}{c}\text { Initial } \\
\text { Particle }\end{array} \\
\text { Size }\end{array}$} & \multicolumn{3}{|c|}{$\begin{array}{l}\text { Particle Size } \\
\text { After }\end{array}$} & \multirow{2}{*}{$\begin{array}{c}\begin{array}{c}\text { Initial } \\
\text { Drug }\end{array} \\
\text { Content }\end{array}$} & \multicolumn{3}{|c|}{$\begin{array}{l}\text { Drug Content } \\
\text { After }\end{array}$} \\
\hline & & & $2 \mathrm{M}$ & $4 \mathrm{M}$ & $6 \mathrm{M}$ & & $2 \mathrm{M}$ & $4 \mathrm{M}$ & $6 \mathrm{M}$ \\
\hline Lyophilized & $4{ }^{\circ} \mathrm{C}$ & $260 \pm 4.6$ & $274.9 \pm 4.6$ & $289.3 \pm 8.2$ & $300.8 \pm 4.5$ & $88.65 \pm 0.33$ & $88.46 \pm 4.2$ & $88.32 \pm 5.8$ & $88.11 \pm 3.5$ \\
\hline \multirow{2}{*}{ MTX-NS } & \multirow{2}{*}{\multicolumn{2}{|c|}{$\begin{array}{l}\text { Room temperature } \\
\qquad 40^{\circ} \mathrm{C}\end{array}$}} & $295.2 \pm 5.9$ & $325.9 \pm 7.1$ & $365.7 \pm 6.8$ & & $87.23 \pm 6.8$ & $87.10 \pm 6.6$ & $87.09 \pm 2.6$ \\
\hline & & & $280.4 \pm 5.4$ & $336.9 \pm 5.6$ & $388.5 \pm 7.2$ & & $87.99 \pm 7.2$ & $87.57 \pm 8.2$ & $87.65 \pm 4.5$ \\
\hline \multirow{3}{*}{$\begin{array}{l}\text { Liquid } \\
\text { MTX-NS }\end{array}$} & $4^{\circ} \mathrm{C}$ & $246.8 \pm 8.23$ & $254.9 \pm 4.2$ & $269.3 \pm 3.6$ & $280.8 \pm 6.3$ & $99.86 \pm 7.4$ & $99.70 \pm 7.8$ & $99.55 \pm 6.1$ & $99.29 \pm 6.6$ \\
\hline & Room temperatu & & $268.2 \pm 4.6$ & $290.9 \pm 4.2$ & $321.7 \pm 2.8$ & & $99.64 \pm 5.9$ & $99.44 \pm 8.1$ & $99.05 \pm 7.2$ \\
\hline & $40^{\circ} \mathrm{C}$ & & $250.4 \pm 5.5$ & $283.9 \pm 5.3$ & $338.5 \pm 3.3$ & & $99.74 \pm 9.1$ & $99.45 \pm 5.6$ & $99.37 \pm 7.8$ \\
\hline
\end{tabular}

${ }^{\star}$ Mean $\pm \mathrm{SD}(\mathrm{n}=3)$. 
orescent nuclei at a higher amount as compared to AQD treated cells at the same concentration, indicating necrosis of cells followed by the death of cells i.e. they induce apoptosis. The stability studies conclude physical as well as chemical stability of NS, by inhibiting the reaggregation of particles by adsorption of stabilizers on drug particles. Thus, the pieces of evidence obtained from $\mathrm{QbD}$ results prove that it is a helpful tool in the fabrication of NS to improve quality and safety, reduce the manufacturing variability, and reduce the manufacturing cost, a requirement of USFDA.

\section{Conflict of interest}

The authors declare no conflict of interest. The authors alone are responsible for the content and writing of the article.

\section{Acknowledgments}

The authors are grateful to Dr. Babasaheb Ambedkar Research and Training Institute (BARTI), Pune for providing funds to carry out the research work smoothly.

\section{References}

1. C. Lipinski, Am Pharm Rev 2002, 5, 82-85. DOI:10.1016/S0338-9898(02)80223-2

2. V. Patravale, A. A. Date and R. Kulkarni, J Pharm Pharmaco 2004, 56, 827-840. DOI:10.1211/0022357023691

3. V. R. Patel, Y. K. Agrawal, J. Adv. Pharm. Techol. \& Res., 2011, 2 (2), 81-87. DOI:10.4103/2231-4040.82950

4. B. Vora, A. Khopade, V. Jain, S. Jain, and N. Jain, Indian Drugs 1996, 33, 365-373.

5. Gennaro AR. Remington: The Science and Practice of Pharmacy. 19th edition. Mace Publishing Co., 1995, 976, 1267.

6. S. S. Abolmaali, A. M. Tamaddon, and R. Dinarvand, Cancer Chemother Pharmacol 2013, 71, 1115-1130.

DOI:10.1007/s00280-012-2062-0

7. P. Jadhav, C. Bothiraja and A. Pawar, J Pharm Innov 2018, 13, 213-225. DOI:10.1007/s12247-018-9314-4

8. E. Van Roon and M. Van de Laar, Clinical and Experimental Rheumatology-Incl Supplements 2010, 28, S27.

DOI:10.1007/s12247-018-9314-4

9. 1S. Desai, D. Bhagwat, S. Shinde And J. Desouza, Int J App Pharm 2019, 11,43-48. DOI:10.22159/ijap.2019v11i3.30578

10. A. H. Ibrahim, E. Rosqvist, J.-H. Smått, H. M. Ibrahim, H. R. Ismael, M. I. Afouna, A. M. Samy and J. M. Rosenholm, Int J Pharm 2019, 563, 217-227.

DOI:10.1016/j.ijpharm.2019.03.064

11. T. A. Powar and A. A. Hajare, Acta Chim Slov 2020, 67, 283303. DOI:10.17344/acsi.2019.5441

12. R. Yadollahi, K. Vasilev and S. Simovic, J Nanomater 2015, 1-13. DOI: $10.1155 / 2015 / 216375$

13. S. Jacob, A. Nair, and J. Shah, Bio Res 2020, 24 (3), 1-16.

\section{DOI:10.1186/s40824-020-0184-8}

14. R. Jayaprakash, K. Krishnakumar, B. Dineshkumar, R. Jose and S. Nair, Sch Acad J Pharm 2016, 5(5), 138-141.

DOI:10.36347/SAJP

15. H.Purkayastha and S. Imanur Hossian, Int J Curr Pharm Res 2019, 11(3), 1-3. DOI:10.22159/ijcpr.2019v11i3.34098

16. S. Hussain, A. Baquee Ahmed, and J. Debnath, Int J Pharm Sci Res 2020, 11(10), 4822-4832.

DOI:10.13040/IJPSR.0975-8232

17. J. Cook, M. T. Cruañes, M. Gupta, S. Riley and J. Crison, AAPS PharmSciTech 2014, 15, 140-148.

DOI:10.1208/s12249-013-0043-1

18. Q. Huang, H. Yu, and Q. Ru, J Food Sci 2010, 75, R50-R57. DOI:10.1111/j.1750-3841.2009.01457.x

19. S. Kalvakuntla, M. Deshpande, Z. Attari and K. Kunnatur, Adv Pharma Bull 2016, 6, 83. DOI:10.15171/apb.2016.013

20. C. P. Dora, S. K. Singh, S. Kumar, A. K. Datusalia and A. Deep, Acta Pol Pharm 2010, 67, 283-90.

DOI:acta_pol_2010/3_2010/283-290

21. N. S. K. Srinivas, R. Verma, G. P. Kulyadi and L. Kumar, Int J Nanomed 2017, 12, 15. DOI:10.2147/IJN.S122729

22. F. Yerlikaya, A. Ozgen, I. Vural, O. Guven, E. Karaagaoglu, M. A. Khan and Y. Capan, J Pharm Sci 2013, 102, 3748-3761. DOI:10.1002/jps.23686

23. L. Rabelo, N. Monteiro, R. Serquiz, P. Santos, R. Oliveira, A. Oliveira, H. Rocha, A. H. Morais, A. Uchoa and E. Santos, Marine drugs 2012, 10, 727-743. DOI:10.3390/md10040727

24. A. A. Abdelbary, A. M. Al-Mahallawi, M. E. Abdelrahim, and A. M. Ali, Int J Nanomed 2015, 10, 6339-6353.

DOI:10.2147/IJN.S91631

25. H. C. Vadlamudi, P. R. Yalavarthi, B. R. M. Venkata, J. Thanniru, K. Vandana and C. Sundaresan, J Acute Dis 2016, 5, 315-325. DOI:10.1016/j.joad.2016.05.004

26. P.F. Yue, Q. Zheng, B. Wu, P.-Y. Hu, Z.-F. Wu and M. Yang, $J$ Dispers Sci Technol 2012, 33, 213-222.

DOI:10.1080/01932691.2011.561162

27. J. He, Y. Han, G. Xu, L. Yin, M. N. Neubi, J. Zhou and Y. Ding, RSC Advances 2017, 7, 13053-13064. DOI:10.1039/C6RA28676C

28. A. Sattar, D. Chen, L. Jiang, Y. Pan, Y. Tao, L. Huang, Z. Liu, S. Xie and Z. Yuan, Sci Rep 2017, 7, 1-9. DOI:10.1038/s41598-017-02523-4

29. A. Fernandes, C. Pydi, R. Verma, J. Jose, and L. Kumar, Braz J Pharm Sci 2020, 1-14.

DOI:10.1590/s2175-97902019000318069

30. N. Bhaskaran, L. Kumar, M. Reddy, and G. Pai, Acta Pharm 2021, 71(1), 57-79. DOI:10.2478/acph-2021-0008 


\section{Povzetek}

Z uporabo pristopa »Quality by design« (QbD) je bila za razvoj nanosuspenzije metotreksata (MTX-NS) uporabljena metodologija visokotlačnega homogenizatorja (HPH) za povečanje biološke uporabnosti. Diagram Ishikawa je bil uporabljen za analizo možnih dejavnikov tveganja pri razvoju formulacij. Za pregled in proučevanje vpliva različnih formulacijskih in procesnih dejavnikov na kritične atribute kakovosti (CQA) sta bila uporabljena zasnova Placket -Burman in osrednja kompozitna zasnova. Število ciklov HPH, koncentracija poloksamera 188 in koncentracija tween 80 so se izkazali za pomembne parametre $(\mathrm{P}<0.05)$, ki so bili dodatno optimizirani z uporabo osrednje kompozitne zasnove. Zeta potencial optimiziranega liofiliziranega MTX-NS je bil $-11.6 \pm 7.52 \mathrm{mV}$, povprečna velikost delcev pa je bila $260 \pm$ $0.25 \mathrm{~nm}$. Poskusi citotoksičnosti in vitro so pokazali več kot $80 \%$ inhibicijo, pri čemer je prišlo do skrčenja apoptotičih celic, fragmentacije in celične smrti. Poleg tega sta se $\mathrm{C}_{\max }$ in $\mathrm{AUC}_{0-\mathrm{t}}$ povečala za 2.53, oziroma 8.83 krat. Ugotovljeno je bilo, da je relativna biološka uporabnost MTX-NS 8.83-krat večja kot pri vodni disperziji MTX. Posledično je metoda QbD omogočila razvoj liofiliziranega MTX-NS z razumevanjem procesov in nadzorom, ki temelji na obvladovanju tveganja kakovosti.

Except when otherwise noted, articles in this journal are published under the terms and conditions of the Creative Commons Attribution 4.0 International License 